\title{
A 62-ka geomagnetic palaeointensity record from the Taymyr Peninsula, Russian Arctic
}

\author{
Stephanie Scheidt ${ }^{1}$, Matthias Lenz ${ }^{1}$, Ramon Egli ${ }^{2}$, Dominik Brill ${ }^{3}$, Martin Klug ${ }^{4}$, Karl Fabian $^{4,5}$, Marlene \\ M. Lenz ${ }^{1}$, Raphael Gromig ${ }^{1}$, Janet Rethemeyer ${ }^{1}$, Bernd Wagner ${ }^{1}$, Grigory Federov ${ }^{6,7}$, Martin Melles ${ }^{1}$ \\ ${ }^{1}$ Institute of Geology and Mineralogy, University of Cologne, 50674, Germany \\ ${ }^{2}$ Central Institute for Meteorology and Geo-dynamics (ZAMG), Vienna, 1190, Austria \\ ${ }^{3}$ Institute of Geography, University of Cologne, Cologne, 50674, Germany \\ ${ }^{4}$ Geological Survey of Norway (NGU), N-7491 Trondheim, Norway \\ 10 Department of Geoscience and Petroleum, Norwegian University of Science and Technology, Norway \\ ${ }^{6}$ Institute of Earth Sciences, St. Petersburg State University, Russia \\ ${ }^{7}$ Arctic and Antarctic Research Institute, St. Petersburg, Russia
}

Correspondence to: Stephanie Scheidt (Stephanie.Scheidt@uni-koeln.de)

\begin{abstract}
This work represents the first palaeomagnetic study carried out on the sedimentary record of lake Levinson-Lessing, which is the deepest lake in northern Central Siberia. Palaeomagnetic analyses were carried out on 730 discrete samples from the upper $38 \mathrm{~m}$ of the $46 \mathrm{~m}$-long core Co1401, which was recovered from the central part of the lake. Alternating field demagnetisation experiments were carried out to obtain the characteristic remanent magnetisation. The relative palaeointensity is determined using the magnetic susceptibility, the anhysteretic remanent magnetization and the isothermal remanent magnetization for normalization of the partial natural remanent magnetization. The chronology of Co1401 derives from accelerated mass spectrometer radiocarbon ages, optically stimulated luminescence dating, and correlation of the relative palaeointensity of 642 discrete samples with the GLOPIS-75 reference curve. This study focuses on the part $>10$ ka but although includes preliminary results for the upper part of the core. The record includes the geomagnetic excursions Laschamps and Mono Lake, and resolves sufficient geomagnetic features to establish a chronology that continuously covers $\sim 62 \mathrm{ka}$. The results reveal continuous sedimentation and high sedimentation rate between 45 and $95 \mathrm{~cm} \mathrm{ka}^{-1}$. High lock-in depths are suggested from the low variability of the magnetic record compared to data sets of reference records with lower sedimentation rate. Although the horizontal component of the characteristic remanent magnetization can only be used with caution because Co1401 was cored without core segment overlap, the magnetic record of Co1401 is the only high-resolution record of relative palaeointensity and palaeosecular variations from the Arctic tangent cylinder going back to $\sim 62 \mathrm{ka}$.
\end{abstract}




\section{Introduction}

The study of past variations of the Earth's magnetic field (EMF) in the Arctic is important for palaeomagnetic, palaeoenvironmental, and palaeoclimatic research. From the palaeomagnetic point of view, most of the Arctic lies inside the tangent cylinder of the inner core and thus records magnetic field variations generated by convection in the northern magnetohydrodynamically closed compartment of the inner core. These variations are expected to be at least partially independent from the global pattern of secular variation (St-Onge and Stoner, 2011; Lund et al., 2016). Therefore, analyses of multiple high-latitude Arctic records are needed to understand this magnetohydrodynamic regime. From the perspective of palaeoenvironmental and palaeoclimatic research, the Arctic region has a considerable impact on the climate of temperate latitudes through a variety of interactions (Christensen et al., 2013). Thus, the much higher warming recently detected in this region makes the Arctic a key region for the understanding of the Earth's climate system. For these studies, palaeomagnetic data provide a chronological tool, which is of particular importance at high latitudes, where the establishment of robust chronologies for sedimentary successions is very challenging (Alexanderson et al., 2014). Lacustrine sediment successions are particularly valuable for studying the magnetic and environmental history in the Arctic, because they often exhibit more continuous and undisturbed deposition with high accumulation rates compared to marine sediments. However, most lake sediment records in the Arctic are limited to a restricted age range, due to glacial erosion during the Last Glacial Maximum and the limited age of sedimentary basins in permafrost landscapes with small tectonic activity. Consequently, continuous sedimentary archives extending beyond the LGM are exceptionally rare in this region.

The Russian-German project PLOT (Paleolimnological Transect), aims at expanding the data base of sedimentary records in the Arctic. For this purpose, sediment cores were obtained from lakes located along a $6000 \mathrm{~km}$ long latitudinal transect across northern Russia. Lake Levinson-Lessing is the northernmost lake of this transect, located on the Taymyr Peninsula, $50 \mathrm{~km}$ northwest of Lake Taymyr (Fig. 1a). The well-stratified sediment infill of this lake is a target for palaeoenvironmental and paleoclimatic studies since the 1990's. Analyses of a first $22.4 \mathrm{~m}$-long sediment core PG1228 revealed continuous sedimentation with nearly constant sedimentation rates of $\sim 70 \mathrm{~cm} \mathrm{ka}^{-1}$ within the past $\sim 32 \mathrm{ka}$ (Ebel et al., 1999; Andreev et al., 2003). Seismic surveys suggesting the presence of up to $115 \mathrm{~m}$ of undisturbed sediments (Niessen et al., 1999; Lebas et al., 2019) motivated a second coring campaign in the central part of the lake in 2017, which yielded a 46-m-long record at site Co1401 (Fig. 1b). Scheidt et al. (2021a) showed that only the upper $38 \mathrm{~m}$ of the associated composite core Co1401 are undisturbed and that this upper part is highly suitable for palaeomagnetic analyses.

Here, we present the first paleomagnetic study of lake Levinson-Lessing sediments and compare the relative palaeointensity (RPI) variations of core Co1401 with the most recent version of GLOPIS-75 palaeointensity stack (Laj et al., 2014; Laj and

Kissel, 2015). The chronology is supported by accelerated mass spectrometer (AMS) radiocarbon $\left({ }^{14} \mathrm{C}\right)$ ages and optically stimulated luminescence (OSL) dating. This work provides new information on the behaviour of the Earth's magnetic field in the Eurasian Arctic during the Late Quaternary and forms the chronostratigraphic backbone for upcoming palaeoenvironmental studies in the region. 
https://doi.org/10.5194/gchron-2021-12

Preprint. Discussion started: 3 June 2021

(c) Author(s) 2021. CC BY 4.0 License.
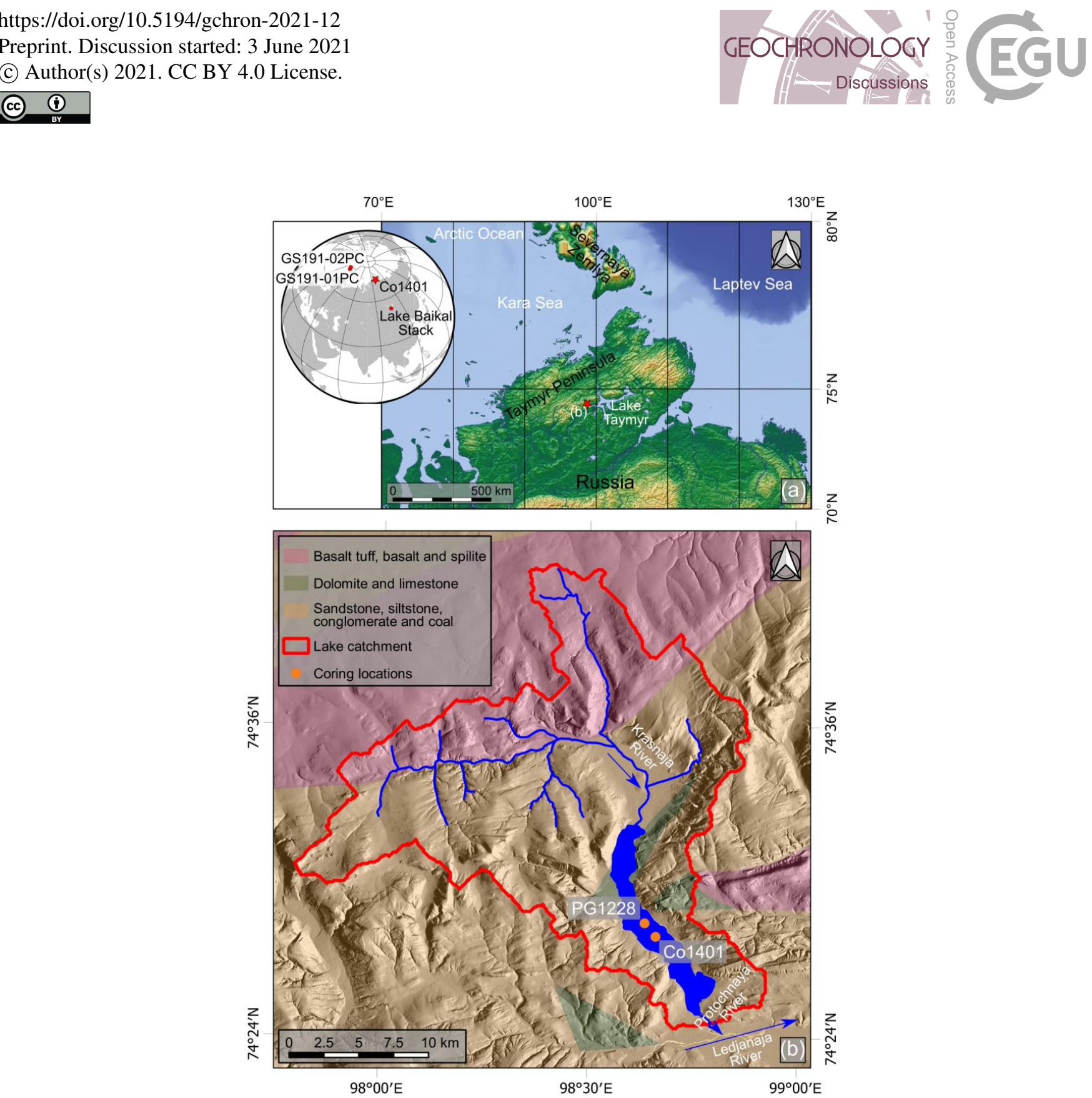

Fig. 1: (a) Global location of the coring sites of Co1401 (red star) and of further records discussed in this study (red dots). The map shows the location of lake Levinson-Lessing to the west of lake Taymyr on the northern Taymyr Peninsula in the Russian Arctic (red star). Map created using GMT 6 (Wessel et al., 2019). (b) Map showing the coring sites Co1401 and PG1228 and the main geological units over the catchment area of lake Levinson-Lessing. Topography is based on ArcticDEM (Porter et al., 2018)

\section{Study area}

Lake Levinson-Lessing is located in the southern Byrranga Mountains on the Taymyr Peninsula in northern central Siberia $\left(74^{\circ} 25^{\prime}\right.$ to $74^{\circ} 32^{\prime} \mathrm{N}$ and $99^{\circ} 33^{\prime}$ to $99^{\circ} 48^{\prime} \mathrm{E}$; Fig. 1). It follows a tectonic trench, which was glacially reshaped in the Early Weichselian (Niessen et al., 1999). The lake basin is $15 \mathrm{~km}$ long, up to $2 \mathrm{~km}$ wide, and covers an area of approximately $25 \mathrm{~km}^{2}$. With a maximum water depth of $\sim 120 \mathrm{~m}$, Lake Levinson Lessing is the deepest lake of the Taymyr Peninsula. The water column of Lake Levinson-Lessing is characterized by generally low nutrient and oxygen availabilities in winter times (Ebel et al., 1999). 
The catchment of Lake Levinson-Lessing covers an area of $\sim 500 \mathrm{~km}^{2}$ (Fig. 1b). The main tributary is the Krasnaya River, which enters the lake at the northern shore. Additional water and sediment supply are provided by 20 ephemeral streams, draining the adjacent eastern and western slopes especially during snow-melt and intensive rainfall events (Bolshiyanov and Anisimov, 1995). The only outflow is the Protochnaya River in the south, which drains lake Levinson-Lessing via the Ledjanaya River and lake Taymyr, and the lower Taymyr River into the Kara Sea of the Arctic Ocean.

The surrounding Byrranga Mountain range consists of weakly metamorphosed to unmetamorphosed Palaeozoic rocks that have been repeatedly folded and faulted (Anisimov and Pospelov, 1999; Torsvik and Andersen, 2002). The largest part of the catchment of Lake Levinson-Lessing is formed by Permian conglomerates, sandstones and siltstones with intercalated coal beds (Gromov et al., 2014; Fig. 1b). Small outcrops of Upper Silurian and Lower to Middle Devonian carbonate-rich limestones and dolomites are restricted to the slopes along the central part of the lake`s catchment. The northernmost part of the catchment is built up of extrusive and intrusive rocks of the Taimyr igneous suite (Walderhaug et al., 2005), which reflect basaltic magmatism during the Upper Permian and Lower Triassic.

The modern climate on the northern Taymyr Peninsula is characterized by typical permafrost conditions with up to eight months-long severe winters (mean January temperatures $-34^{\circ} \mathrm{C}$ ) and short cold summers (mean July temperatures of $\sim 6^{\circ} \mathrm{C}$ ) (Siegert and Bolshiyanov, 1995). The frost-free period is approx. 50 days per year.

\section{Material and methods}

\subsection{Coring of Co1401 and core lithology}

Co1401 is a composite core of $6.3 \mathrm{~cm}$ diameter that was retrieved from $\sim 112 \mathrm{~m}$ water depth in the central part of Lake Levinson-Lessing $\left(74^{\circ} 27^{\prime} 53.64 " \mathrm{~N}, 9^{\circ} 39^{\prime} 58.03\right.$ "E; Fig. 1b) in early 2017. Whilst the upper $134 \mathrm{~cm}$ of the core were recovered with a gravity corer, the remaining part consists of a succession of 24 cores, each with a maximum length of $2 \mathrm{~m}$, which were retrieved with a percussion piston corer (both UWITEC, AT). The composite record has a total length of $45.95 \mathrm{~m}$, with gaps of 2 to $36 \mathrm{~cm}$ between individual piston cores. Scheidt et al. (2021a) found that only the uppermost $38 \mathrm{~m}$ composite depth (mcd) are undisturbed, whereas the four piston cores below contain sediment collected on their way to the target depths. Therefore, only the upper $38 \mathrm{mcd}$ of Co1401 are considered in this study.

105 This undisturbed part of the core consists of fine-layered, hemipelagic sediments, dominantly composed of silt. Frequent and irregular incisions of turbidites intercalate the background sedimentation and result in a widely continuous sediment accumulation punctuated by short-term peaks. Turbidite thicknesses are $<8 \mathrm{~cm}$ with grain sizes up to fine sand at the base and clay at the top. However, most of the sediment sequence is finely layered without signs of bioturbation. Organogenic material, comprising terrestrial and aquatic macro remains as well as charcoal, is present in low concentration.

Before the core segments were opened, whole-core palaeomagnetic measurements with alternating field (AF) demagnetization to peak fields of up to $15 \mathrm{mT}$ were conducted at the Leibniz Institute for Applied Geophysics (LIAG) (Scheidt et al., 2021a). The cores were then split lengthwise at the University of Cologne, where the surface of one core half was cleaned to obtain high-resolution line-scan images. Hereafter, XRF-scanning was performed at $2 \mathrm{~mm}$ resolution (exposure time of $20 \mathrm{sec}$.) using 115 an ITRAX core scanner (Cox Analytical Systems, SE) equipped with a $1.9 \mathrm{kV} \mathrm{Cr} \mathrm{X-ray} \mathrm{source} \mathrm{and} \mathrm{a} \mathrm{Si-drift} \mathrm{detector} \mathrm{in}$ combination with a multi-channel analyser (voltage: $30 \mathrm{kV}$, amperage: $55 \mathrm{~mA}$ ). Total carbon (TC) and total inorganic carbon (TIC) were measured on 345 samples of finely grinded $(<63 \mu \mathrm{m})$ sediment material using a DIMATOC 2000 (Dimatec Analysentechnik GmbH, DE). Total organic carbon (TOC) was calculated from the difference between TIC and TC. 


\subsection{Discrete sample palaeomagnetic analyses}

The entire core composite was subsampled continuously in $2.1 \mathrm{~cm}$ intervals using $6.3 \mathrm{~cm}^{3}$ plastic boxes. From the resulting sample set, 730 turbidite-free samples were selected for measurements at the cryogenic magnetometer laboratory of the Geological Survey of Norway in Trondheim (NGU). The magnetic susceptibility $(\chi)$ was determined using a Bartington MS3 with an attached MS2B single-sample sensor (low frequency mode, 5 sec. measurement time). The natural remanent magnetization (NRM), anhysteretic remanent magnetization (ARM), and isothermal remanent magnetization (IRM) were measured using the horizontal SQUID SRM (2G Enterprises, US). NRM measurements were followed by stepwise AF demagnetization in peak fields of $5,10,15,20,25,30,35,40,50,60,70$, and $80 \mathrm{mT}$ using a $2 \mathrm{G} 600 \mathrm{AF}$ Demagnetizer. Thereafter, an ARM (80 mT peak AF, $100 \mu \mathrm{T}$ bias field) and finally a $900 \mathrm{mT}$ IRM were imparted. ARM and IRM were both AF demagnetized using the peak fields specified above. NRM and ARM measurements were visually inspected and corrected for individual flux jumps or SQUID miscounts. The results of the IRM measurements were not corrected because single flux jumps or SQUID miscounts even after demagnetization is far below $1 \%$ and does not influence the paleomagnetic interpretation.

The characteristic remanent magnetization (ChRM) was determined by principal component analyses (Kirschvink, 1980) of NRM demagnetization curves using the software Remasoft 3.0 (Chadima and Hrouda, 2006). In most cases, five consecutive AF demagnetization steps between $15 \mathrm{mT}$ and $80 \mathrm{mT}$ were used to determine the ChRM. Fits were anchored at the origin only when clustering of individual horizontal components prevented the determination of a meaningful direction. Because the core is not oriented to the north, the first core section was rotated to adjust magnetic declination of the topmost sample with the present-day value at the site. Subsequently, the underlying cores were oriented one after the other to obtain a smooth declination record. The RPI was determined by the pseudo-Thellier method of Tauxe et al. (1995) using the partial NRM (pNRM) between 30 and $50 \mathrm{mT}$ demagnetization steps, and magnetic susceptibility, ARM, or IRM as normalizers.

\subsection{Reference records for RPI correlation}

Ideally, the reference data used for RPI comparison should come from nearby sites characterized by continuous and high sedimentation rates, and should be supported by a robust age model. Unfortunately, there are no terrestrial or marine data with these properties within $<1500 \mathrm{~km}$ of Levinson-Lessing Lake, which go back far enough in time. Comparison records without severe glacial overprints are extremely rare even over the entire Arctic Circle. Furthermore, not all records that fulfil the prerequisites for palaeomagnetic analyses (Tauxe, 1993; Stoner and St-Onge, 2007) have been measured with sufficient resolution, existing data sets are often not accessible. Another important issue is the change of age references with the advancement of absolute dating methods in context with data documentations. Thereby, the age models of a large number of records are no longer up to date and cannot always be transferred to recent age models. With these considerations in mind, the RPI pattern of core Co1401 is discussed using the following reference records:

- Sites PS2644-5, MD95-2009, SU90-24, ODP984, P012 and P013, which are the northern high-resolution individual records of the GLOPIS-75 stack (Laj et al., 2004). GLOPIS-75 was compiled with RPI data from 24 sites in the northern and southern hemispheres. Its age model is based on $\mathrm{K}-\mathrm{Ar}$ and ${ }^{40} \mathrm{Ar} /{ }^{39} \mathrm{Ar}$ dated lava flows and was recently updated using the GICC05 age model of the NGRIP ice core (Laj et al., 2014; Laj and Kissel, 2015). The names GLOPS-75 and GLOPIS75-GICC05 will be used in the following to distinguish between GLOPIS-75 records with the former and the new time scale, respectively.

- Cores GS191-01PC and GS191-02PC from the southwestern margin of the Svalbard Archipelago in the Barents Sea (Caricchi et al., 2019). The $17.37 \mathrm{~m}$ and $19.67 \mathrm{~m}$ long records cover the last $\sim 42 \mathrm{ka}$ and $\sim 58 \mathrm{ka}$, respectively, and represent 
the most complete records available for similar latitude $\left(76^{\circ} 31^{\prime} \mathrm{N}\right.$ and $77^{\circ} 35^{\prime} \mathrm{N}$, respectively) and time span. The age models of the cores rely on AMS ${ }^{14} \mathrm{C}$ measurements, the identification of lithostratigraphic features (e.g., Heinrich events and meltwater events), and correlation with the GLOPIS-75 stack, as well as with the geomagnetic field models SHA.DIF14k (Pavón-Carrasco et al., 2014) and GGF100k (Panovska et al., 2018).

- A stacked palaeomagnetic record from the sediments of Lake Baikal (Siberia) over the last 84 ka (Peck et al., 1996). Although Lake Baikal is located $\sim 1500 \mathrm{~km}$ away from Levinson-Lessing Lake at $50^{\circ} 30^{\prime} \mathrm{N}$, it is the nearest available lacustrine record covering the necessary time span with sufficient resolution. The age model of the Baikal stack is based on AMS ${ }^{14} \mathrm{C}$ ages and the correlation of rock magnetic climate proxy data to the marine oxygen isotope record of Martinson et al. (1987).

\subsection{Optically stimulated luminescence dating}

Optically stimulated luminescence (OSL) dating was carried out on four samples at the Cologne Luminescence Laboratory of the University of Cologne. The sampled material was obtained from core catchers, which were pushed into opaque liners immediately after core retrieval to exclude light exposure. Samples for burial dose determination were processed under subdued red-light conditions and pre-treated following standard procedures to extract the 4-11 $\mu$ m quartz fraction (e.g., Zander and Hilgers, 2013). Samples were pipetted on $9.8 \mathrm{~mm}$ steel discs and measured on a Ris $\varnothing$ TL/OSL reader with a ${ }^{90} \mathrm{Sr} /{ }^{90} \mathrm{Y}$ beta source delivering $\sim 0.11 \mathrm{~Gy} \mathrm{~s}^{-1}$ at the sample position. Luminescence signals were stimulated by means of blue LEDs and detected through a Hoya U340 filter. Equivalent dose measurements followed the SAR protocol of Murray and Wintle (2003), with an experimentally determined preheat at $220^{\circ} \mathrm{C}$ for $10 \mathrm{sec}$ and a cutheat at $200{ }^{\circ} \mathrm{C}$. The appropriateness of the applied protocol was checked by means of preheat tests, dose recovery tests, and $\mathrm{CW}$-curve fitting that indicate dose independence of preheat temperatures, reproducibility of laboratory doses and a dominant fast component. For each sample 10 aliquots were measured and passed standard SAR acceptance criteria. Since equivalent dose distributions with over-dispersion values of less than $5 \%$ gave no indication of incomplete resetting of quartz luminescence signals, burial dose calculation was based on the central age model (Galbraith et al., 1999). The dosimetry was based on uranium, thorium and potassium contents of the surrounding sediment derived from high-resolution gamma spectrometry measured at the VKTA Rossendorf. Measured water contents were corrected for the effects of compaction during the burial period following Buylaert et al. (2013). Dose rate and age calculation were performed using the DRAC software version 1.2 (Durcan et al., 2015).

\subsection{Radiocarbon dating}

AMS ${ }^{14} \mathrm{C}$ dating on macro-organic remains was carried out on ten samples. Wherever applicable, macro remains were retrieved directly from the sediment core after core opening and during subsampling. In most cases, however, they had to be isolated from 1-4 g subsamples, which were sieved using mesh widths of 125, 63, and $36 \mu \mathrm{m}$. In the isolated fractions, larger organic remains were picked out by hand and smaller ones isolated by density separation. For the latter, a heavy-density solution consisting of sodium polytungstate (calibrated to $2.3 \mathrm{~g} \mathrm{~cm}^{-3}$ ) was added to the samples. After 15 min of centrifugation at $2500 \mathrm{rpm}$, the lighter material floating at the top was pipetted off the solution. This step was repeated three times. Finally, the extracted material was rinsed using deionized water to remove and dissolve any residual sodium polytungstate. The isolated bulk organic and terrestrial plant remains were pretreated according to the standard protocol for organic materials and converted to elemental carbon by graphitization (Rethemeyer et al., 2019). Samples were measured at the CologneAMS centre at the University of Cologne. Radiocarbon dates were calibrated to calendar years BP (AD 1950) using the IntCal20 calibration curve for terrestrial northern hemisphere material (Reimer et al., 2020). 


\section{Results and discussion}

\subsection{Magnetic mineralogy and selected geochemical properties}

The magnetic mineralogy of Co1401 was investigated in Scheidt et al. (2021a) to determine the suitability of this core for palaeomagnetic investigations (Tauxe, 1993; Stoner and St-Onge, 2007). Results suggest that the main remanence carriers of Co1401 are $\leq 5 \mu \mathrm{m}$ pseudo-single domain (titano-) magnetite and maghemite. Additionally, up to $8 \%$ of the saturation remanent magnetization is carried by single domain particles. The contribution of multi-domain particles is generally low. The magnetic mineralogy appears to be exceptionally homogeneous between 6.7 and 38 mcd. Above 6.7 mcd, bulk hysteresis parameters suggest smaller magnetic grain sizes, but still in the PSD range. As documented by first-order reversal curves, this apparent fining is due to the additional contribution of single domain greigite. The maximum contribution of greigite to the saturation remanence is negligible in the $0-20 \mathrm{mT}$ range but reaches $\sim 50 \%$ above $\sim 50 \mathrm{mT}$ at $\sim 3 \mathrm{mcd}$. Based on these results, samples collected from Co1401 are generally well suited for RPI studies, although caution should be exercised in the upper meters.

After careful inspection of the measurement data, 89 samples were discarded (red dots in Fig. 2), for the following reasons.

First, sections with erratic, discontinuous ChRM directions were assumed to be affected by core disturbances. However, if inconsistent ChRM directions occurred only near the cut edges of the cores, the corresponding RPI values were not discarded, because directional changes may occur at the top and bottom of the core section due to the division of the cores and compression of the core ends during transport. Second, samples with unstable demagnetization behaviour and those that were almost completely demagnetized in $\leq 30 \mathrm{mT}$ were considered unreliable. Third, samples at the end of core sections with significantly lower NRM values than adjacent samples were discarded because likely affected by oxidation of unstable remanence carriers. Fourth, samples with particularly elevated NRM values ( $\geq 2$ times larger than adjacent samples) or Fe/Ti ratios were assumed to be lithologically different from the surrounding samples. Such differences could be caused, for example, by turbidite horizons that were overlooked during sample selection.

Samples that passed the above selection criteria are characterized by consistently low and stable values in the Fe/Ti ratio (Fig. 2), which are generally interpreted as an expression of relatively stable redox conditions (cf., van der Bilt et al., 2015). It is important to note, however, that initial greigite formation in the uppermost meters is not detected by this proxy, because the onset of redox conditions first affect the smallest particles of the magnetic mineral fraction, which represent only a small portion of the total Fe content. Sample selection resulted also in a reduction of the already low scatter of NRM, $\chi$, ARM, and IRM values (Fig. 2). Interestingly, downcore variations of the overall low total organic carbon (TOC) content of Co1401 are anticorrelated with concentration-dependent magnetic parameters (Fig. 2). In the upper 6.7 med a change in the environmental conditions is likely to cause the decrease in these magnetic parameters and the increase of TOC. Below $6.7 \mathrm{mcd}$, the anticorrelation might be explained by a sorting effect, with finer detrital material originating from more vegetated areas. Different sources of the deposited material are rather unlikely, since no variations of the lithogenic mineral magnetic composition has been detected (Scheidt et al., 2021a). 
https://doi.org/10.5194/gchron-2021-12

Preprint. Discussion started: 3 June 2021

(c) Author(s) 2021. CC BY 4.0 License.

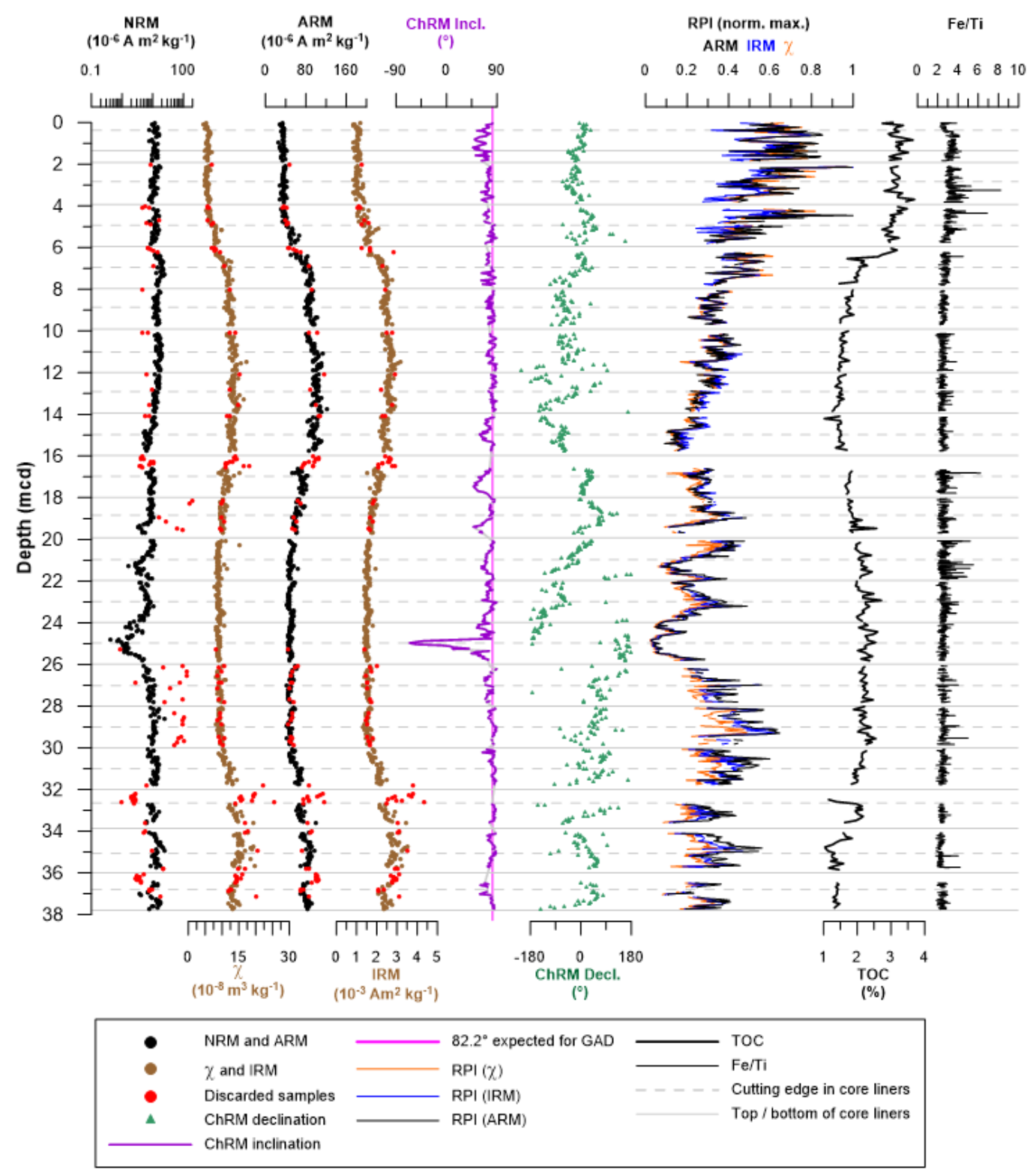

Fig. 2: Downcore plots of magnetic and chemical parameters in core Co1401. Discarded samples are not depicted in the ChRM inclination and declination, nor in the RPI and Fe/Ti ratio. The RPI is calculated using three different normalizers. Please note that the NRM is presented on a logarithmic scale.

\subsection{Basic chronology of core Co1401}

OSL (Table 1) and the AMS ${ }^{14} \mathrm{C}$ (Table 2) dating results suggest a quite regular sediment accumulation with an age of $\sim 60 \mathrm{ka}$ at the base of the succession (Fig. 3). Overall, OSL yields slightly younger ages than ${ }^{14} \mathrm{C}$ dating. Age differences between the two dating methods may arise from redeposition of old organic macro remains or hard-water effects on ${ }^{14} \mathrm{C}$ ages. On the other hand, OSL results may be influenced by unaccounted changes of the water content, due to insufficient correction of sediment 
https://doi.org/10.5194/gchron-2021-12

Preprint. Discussion started: 3 June 2021

(c) Author(s) 2021. CC BY 4.0 License.

compaction, or incomplete luminescence signal resetting prior to sedimentation (Lang and Zolitschka, 2001; Buylaert et al., 2013).

Table 1: Optically stimulated luminescence data and ages. Short names are used in the figures and discussion of this study. $\mathbf{N}-$ number of aliquots used for burial dose calculation, OD - over-dispersion, De - Equivalent dose, $W_{\text {mod }}$ - measured water contents corrected for the effect of sediment compaction, DR - dose rate. Ages are provided with 1-sigma uncertainties.

\begin{tabular}{|ccccccccccccc|}
\hline $\begin{array}{c}\text { Short } \\
\text { name }\end{array}$ & Lab-ID & $\begin{array}{c}\text { Depth } \\
(\mathbf{m c d})\end{array}$ & Mineral & $\mathbf{N}$ & $\begin{array}{c}\text { OD } \\
(\%)\end{array}$ & $\begin{array}{c}\text { De } \\
(\mathbf{G y})\end{array}$ & $\begin{array}{c}\mathbf{U} \\
(\mathbf{p p m})\end{array}$ & $\begin{array}{c}\text { Th } \\
(\mathbf{p p m})\end{array}$ & $\begin{array}{c}\mathbf{K} \\
(\%)\end{array}$ & $\begin{array}{c}\mathbf{W}_{\text {mod }} \\
(\%)\end{array}$ & $\begin{array}{c}\text { DR } \\
(\mathrm{Gy} / \mathbf{k a})\end{array}$ & $\begin{array}{c}\text { Age } \\
(\mathbf{k a})\end{array}$ \\
\hline O1 & C- & $9.94-$ & quartz & 10 & 0 & 47.7 & 3.0 & 10.3 & 2.40 & 61 & 2.9 & 17.6 \\
& L4563 & 10.00 & & & & \pm 0.6 & \pm 0.4 & \pm 0.7 & \pm 0.15 & & \pm 0.2 & \pm 1.0 \\
O2 & C- & $21.94-$ & quartz & \multirow{2}{*}{10} & 3 & 96.6 & 3.5 & 10.4 & 2.54 & 56 & 3.2 & 32.6 \\
& L4564 & 22.00 & & & & \pm 2.3 & \pm 0.4 & \pm 0.7 & \pm 0.16 & & \pm 0.2 & \pm 2.1 \\
O3 & C- & $27.94-$ & quartz & \multirow{2}{*}{10} & 5 & 126.9 & 3.3 & 9.4 & 2.30 & 50 & 3.2 & 45.1 \\
& L4565 & 28.00 & & & & \pm 3.9 & \pm 0.5 & \pm 0.6 & \pm 0.15 & & \pm 0.2 & \pm 3.1 \\
O4 & C- & $33.94-$ & quartz & \multirow{2}{*}{10} & 0 & 132.3 & 2.9 & 8.9 & 2.22 & 47 & 3.0 & 48.9 \\
& L4566 & 34.00 & & & & \pm 2.3 & \pm 0.4 & \pm 0.6 & \pm 0.14 & & \pm 0.2 & \pm 3.2 \\
\hline
\end{tabular}

Table 2: Radiocarbon isotope data and ages. Short names are used in the figures and discussion in this study. The macro-remains were too small for an unambiguous identification and may be of mixed aquatic and terrestrial origin. Calibrated ages are given with 2-sigma uncertainty ranges.

\begin{tabular}{|ccccccc|}
\hline $\begin{array}{c}\text { Short } \\
\text { name }\end{array}$ & AMS ID & $\begin{array}{c}\text { Depth } \\
(\mathbf{m c d})\end{array}$ & Dated material & $\mathbf{F}^{\mathbf{1 4}} \mathbf{C}$ & $\begin{array}{c}{ }^{14} \mathbf{C} \text { age } \\
\text { (year BP) }\end{array}$ & $\begin{array}{c}\text { Age } \\
\text { (cal. year BP) }\end{array}$ \\
\hline A & COL5806.1.1 & 0.85 & Macro-remains & $0.6759 \pm 0.0034$ & $3150 \pm 40$ & $3350 \pm 102$ \\
B & COL5807.1.1 & 3.05 & Macro-remains & $0.5177 \pm 0.0041$ & $5290 \pm 60$ & $6094 \pm 169$ \\
C & COL5808.1.1 & 6.45 & Macro-remains & $0.2111 \pm 0.0016$ & $12500 \pm 60$ & $14681 \pm 384$ \\
D & COL5809.1.1 & 10.01 & Macro-remains & $0.0808 \pm 0.0013$ & $20200 \pm 130$ & $24276 \pm 525$ \\
E & COL5810.1.1 & 14.80 & Macro-remains & $0.0751 \pm 0.0023$ & $20800 \pm 240$ & $25024 \pm 610$ \\
F & COL5722.1.1 & 17.49 & Macro-remains & $0.0394 \pm 0.0018$ & $26000 \pm 370$ & $30159 \pm 767$ \\
G & COL5723.1.1 & 22.30 & Macro-remains & $0.0200 \pm 0.0008$ & $31400 \pm 310$ & $35369 \pm 644$ \\
H & COL5724.1.1 & 25.29 & Macro-remains & $0.0113 \pm 0.0017$ & $36000 \pm 1200$ & $40605 \pm 2195$ \\
I & COL6876.1.1 & 33.08 & Macro-remains & $0.0022 \pm 0.0018$ & $49900 \pm 880$ & $52925 \pm 2056$ \\
\hline
\end{tabular}




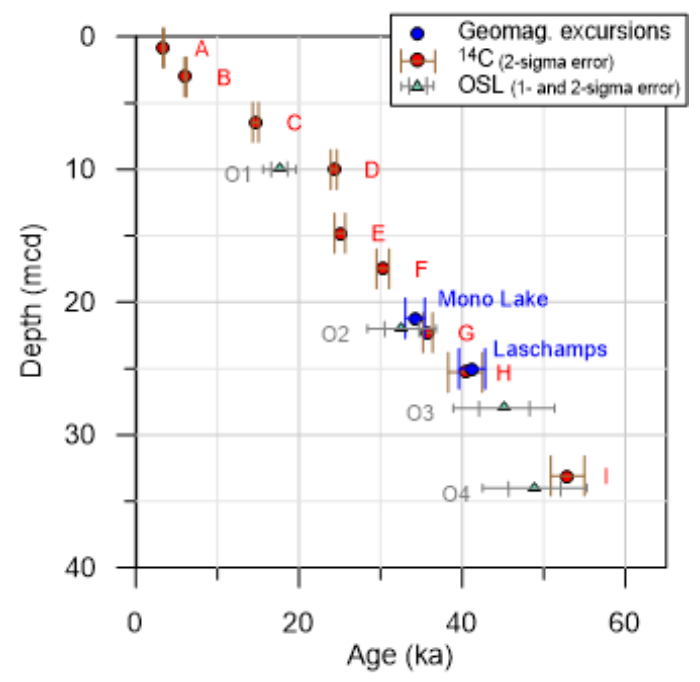

Fig. 3: OSL and AMS ${ }^{14} \mathrm{C}$ dating results of core composite Co1401, and locations of Laschamps and Mono Lake excursions. Ages and age uncertainties of the geomagnetic excursions are taken from Laj et al. (2014).

\subsection{Palaeosecular variations and relative palaeointensity}

AF demagnetisation to $80 \mathrm{mT}$ removes, on average, $92.8 \%$ of the NRM left after the initial $15 \mathrm{mT}$ whole core demagnetization.

A small viscous overprint, which is fully removed after the $15 \mathrm{mT}$ AF step, was observed only in a limited number of samples. Additionally, a few samples around 3 mcd acquired a gyroremanence in fields $>60 \mathrm{mT}$, which is typically related to the presence of greigite (e.g., Scheidt et al., 2015). In the PCA, the ChRM is defined by the steepest part of the AF demagnetization curves, which was generally at higher AF fields in the upper part of the core than in the lower part (Fig. 4a, 4b). Overall, one stable magnetic direction was extracted in all samples. In case of steep inclinations, the horizontal component frequently clusters close to the origin (Fig. 4c). The extracted characteristic inclination varies between $89.7^{\circ}$ and $-66.1^{\circ}$ (Fig. 2), with a mean of $74.5^{\circ}$ and a median of $77.3^{\circ}$, and thereby is slightly less than the $82.1^{\circ}$ of the geomagnetic axial dipole (GAD) expected at the site. This deviation may be due to inclination shallowing, but could also originate from sampling procedures. Besides, the sections with lower inclination values between 16 and $20 \mathrm{mcd}$ and the field reversal at $\sim 25$ mcd reduce the mean and median characteristic inclination value by $2.3^{\circ}$ and $0.6^{\circ}$, respectively. Due to the lack of orientation of the cores with respect to the north direction, and because the individual $2 \mathrm{~m}$-long cores do not overlap, the consecutive rotation of each core section to make the declination curve continuous add a cumulative error that increases with depth. Thus, only relative changes of the characteristic declination within core sections can be considered reliable. In a few cases, sudden changes in declination also have been detected within cores. Here, core parts are probably twisted against each other. Because of these problems, a pole wander curve was not calculated for Co1401. 


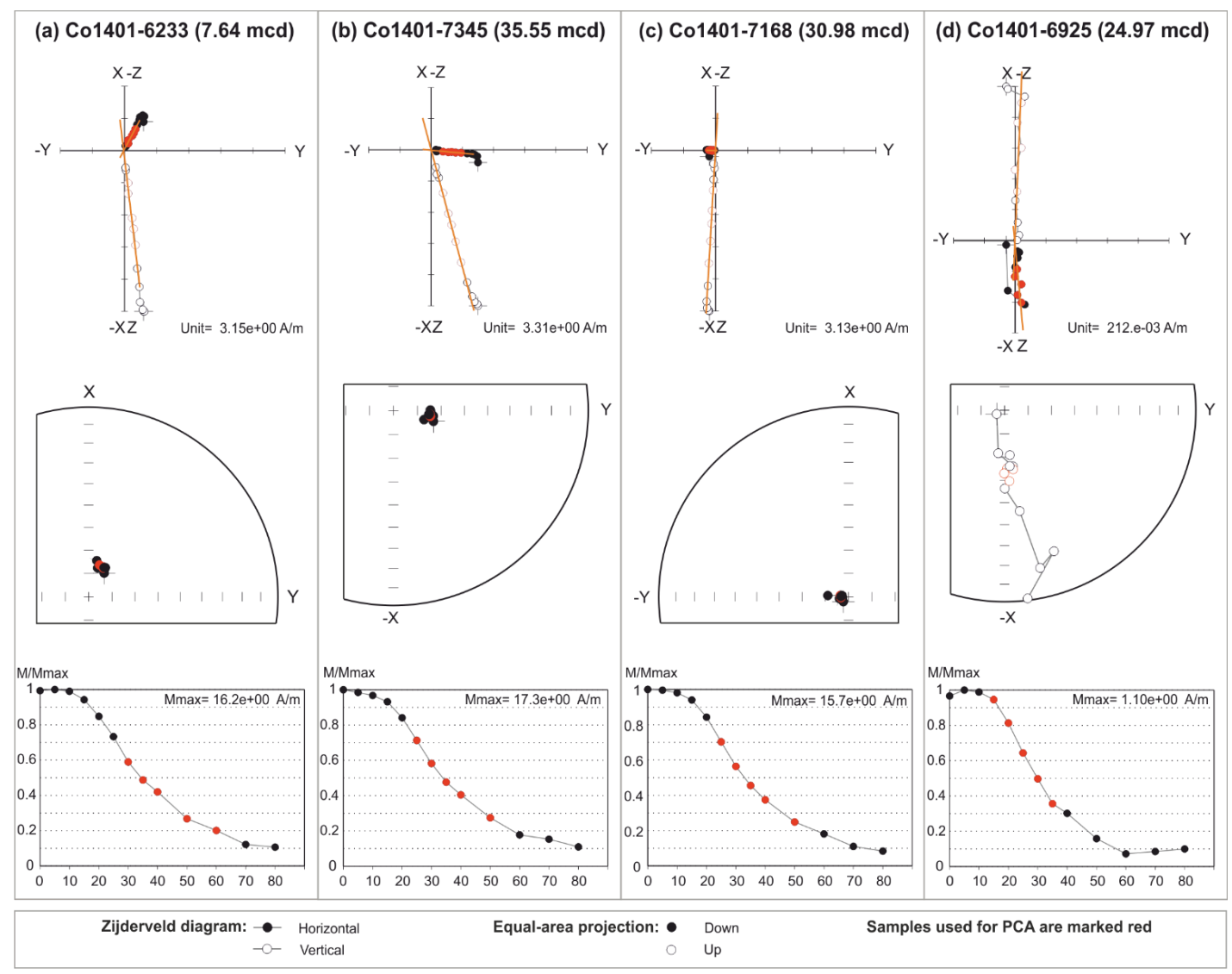

Fig. 4: AF demagnetization characteristics of selected samples. Zijderveld diagrams, equal area projections and normalized NRM intensity are shown in the first, second, and third row, respectively. Points used to define the ChRM are marked in red.

The RPI of Co1401 shows a clear decreasing trend between 0 and $\sim 16 \mathrm{mcd}$, followed by two intervals with relatively constant average values at $\sim 16-25$ and $\sim 25-38 \mathrm{mcd}$, respectively. Short-term fluctuations are superimposed to these trends. Very similar results are obtained with all three normalizers, as expected from the homogeneous magnetic mineralogy (Fig. 2). However, although all normalizers show the same pattern, there is a strong increase in RPI fluctuations from about 7.4 mcd upwards. Especially in the upper 6 mcd the largest scatter and highest RPI values occur. This upward increase in variability is probably due to a change in recording efficiency related to a change in magnetic mineralogy reported at about 6.7 mcd (Scheidt et al., 2021a). Alternatively, or in addition, a misorientation of magnetic minerals caused by compaction of the sediment in the lower part could result in lower RPI values.

The lowest RPI values are displayed around $25 \mathrm{mcd}$ and coincide with the negative values of the characteristic inclination $\left(-66.1^{\circ}\right)$. Age and pattern of this event coincide with those of the Laschamp geomagnetic excursion (e.g., Laj et al., 2006; Li et al., 2018; Simon et al., 2020). It is worth noting that samples around $\sim 25 \mathrm{mcd}$ also show the largest PCA scattering (Fig. $4 d$ ), which is probably caused by the higher influence of measurement noise at low magnetization values. An additional RPI low in $\sim 21.3$ mcd is associated with shallower inclination values rather than true excursional directions and can be attributed to the Mono Lake geomagnetic excursion. The lack of reversed directions for the Mono Lake excursion has been reported before (e.g., Lund et al., 2017). The assigned ages of the two identified geomagnetic excursions are within 2-sigma uncertainty of the absolute dating results (Fig. 3). At $\sim 19.4$ mcd a weakened RPI is combined with shallower inclination values. This 

softened, at about $28 \mathrm{ka}$ in the core PS 2138-1 SL from the Arctic Ocean (Nowaczyk and Knies, 2000). Finally, the lower inclination values at around $17.5 \mathrm{mcd}$ do not correspond to lower RPI values. However, there are no correspondences with a large turbidite, a core end, or a change in the magnetic properties of the rock, nor is there any evidence that this element is a drilling- or sampling-induced artefact.

\subsection{Remanence acquisition in lake Levinson-Lessing}

The chronostratigraphic relevance of a palaeomagnetic sediment sequence depends crucially on the NRM acquisition mechanism. Mineral magnetic analyses of core Co1401 do not suggest significant changes of the recording mechanism. Only in the uppermost part of the succession greigite formation has started. Consequently, it is possible that the magnetic signals of the individual samples from this part of the core integrate over the primary magnetization and a secondary magnetization that arose at any time. Since the greigite formation seems to be initial, we assume the main part of the magnetic signal to be primary. However, this needs to be analysed in greater detail, so the range up to approx. 6.7 mcd should only be considered cautiously at present.

305 For the remaining part of the core, between 6.7 and $38 \mathrm{mcd}$, further comparison with other records require some considerations about the lock-in depth. The lock-in depth is defined as the depth below the sediment-water interface where a post-depositional remanent magnetization (pDRM) becomes locked and contributes to the permanent record. The occurrence and extent of this effect depends on several factors, including water content, grain size, accumulation rate, and bioturbation intensity (e.g., Tauxe et al., 2006; Roberts et al., 2013; Egli and Zhao, 2015; Valet et al., 2017), but the underlying processes are poorly known. Therefore, the lock-in depth is described by an empirical lock-in function representing the fraction of total NRM that is blocked above a given depth (e.g., Nilsson et al. 2018, and references therein). The median and width of the lock-in function, divided by the accumulation rate, give the mean delay and time constant of the recording process, respectively. Large accumulation rates, as in Co1401, ensure that delay and smoothing associated with the lock-in function are minimized. A small delay is essential for establishing a chronology with small uncertainties.

315 Co1401 provides a rare continuity in TOC (Fig. 2) grain size, and water content in most parts of the core. Due to the finegrained composition and soft consistency in the upper meters, a significant lock-in effect is expected. Since an accurate and precise chronology (e.g., varve chronology) for a systematic evaluation of the dimension of the lock-in effect is not available for lake Levinson-Lessing, we refer to recent studies of varved sediments from two lakes in Sweden to obtain a rough estimate of the potential acquisition delay. Similar to our study, the age-depth relationships of lakes Kälksjön and Gyltigesjön indicate high and overall nearly constant sedimentation rates of approximately $59 \mathrm{~cm} \mathrm{ka}^{-1}$ during the past c. $3 \mathrm{ka}$ (Mellström et al., 2015) and approx. $75 \mathrm{~cm} \mathrm{ka}^{-1}$ during the past $6 \mathrm{ka}$ (Snowball et al., 2013), respectively. Furthermore, the preservation of sedimentary structures in these Swedish records largely excludes bioturbation, just as at lake Levinson-Lessing. Yet, reported lock-in depths vary widely for both of the Swedish lakes. Mellström et al. (2015) state the lock-in depth to be between $30 \mathrm{~cm}$ and $80 \mathrm{~cm}$ for Kälksjön Lake, while Nilsson et al. (2018) modelled a half lock-in depth of $16.6 \pm 3.3 \mathrm{~cm}$. A similar variance can be recognized for Gyltigesjön Lake, for which Snowball et al. (2013) specified 21-34 cm. By contrast, Mellström et al. (2015) modelled plausible lock-in depths between 50-160 cm for this lake, and Nilsson et al. (2018) yield a half lock-in depth of $30.7 \pm 6.5 \mathrm{~cm}$ by their approach. For comparison, it is important to note that the half lock-in depth can only be transferred into the lock-in depth by doubling of the value for symmetric lock-in functions (e.g., rectangular or Gaussian), but not for other shapes (linear, cubic or exponential). Besides the choice of the lock-in function, the used geomagnetic field reference curves influence the final estimates. Additionally, Mellström et al. (2015) explain the appropriateness of their exceptionally deep lock-in depth values with the relatively low wet density and high organic content (45-50\% loss-on-ignition; LOI) of the lake`s sediment. Following this argumentation and assuming a LOI to TOC ratio of approximately two (Vereş, 2002; Haflidason et al., 2019), the lock-in depths in lake Levinson-Lessing must be well below those specified by Mellström et al. (2015) for both 
Swedish lakes (cf., section 4.4). Assuming a lock-in depth range of 10-30 cm and a sedimentation rate of $70 \mathrm{~cm} \mathrm{ka}^{-1}$ for lake

\subsection{RPI correlation and implications for Co1401}

Absolute ages from OSL and ${ }^{14} \mathrm{C}$ dating (Table 1, 2; Fig. 3) provide important tie points for the comparison of the RPI record of Co1401 with reference data. Due to the problems with reference datasets described above (section 3.4), we correlate the RPI(ARM) of core Co1401 with the GLOPIS-75 stack and with the six northern, high-resolution records included in this stack, and rely exclusively on its recently updated age model (Fig. 5). Thus, we focus on the time interval covered by these records, which is $>10 \mathrm{ka}$. We decided not to include additional reference records for the younger part of Co1401 for two reasons. First, the presence of greigite associated with the intensification of RPI variation in Co1401 requires a more detailed investigation of the magnetic mineralogy of the individual samples before the RPI can be considered reliable. Second, a large number of RPI records are available for the Holocene providing many and complex perspectives for the discussion, which would go beyond the scope of this publication. As a preliminary result, the range $<10 \mathrm{ka}$ is therefore only correlated with the virtual axial dipole moment (VADM) of GLOPIS-75-GICC05 that show a general trend of the intensity variation of the last $10 \mathrm{ka}$ (Fig. 5). For the older part of the record, 12 additional tie lines were defined. Due to the natural variability of the EMF, the influence of sedimentological properties on records, and possible inaccuracies of the applied age models of the reference records, not all of these tie lines connect identically shaped features. 
https://doi.org/10.5194/gchron-2021-12

Preprint. Discussion started: 3 June 2021

(c) Author(s) 2021. CC BY 4.0 License.

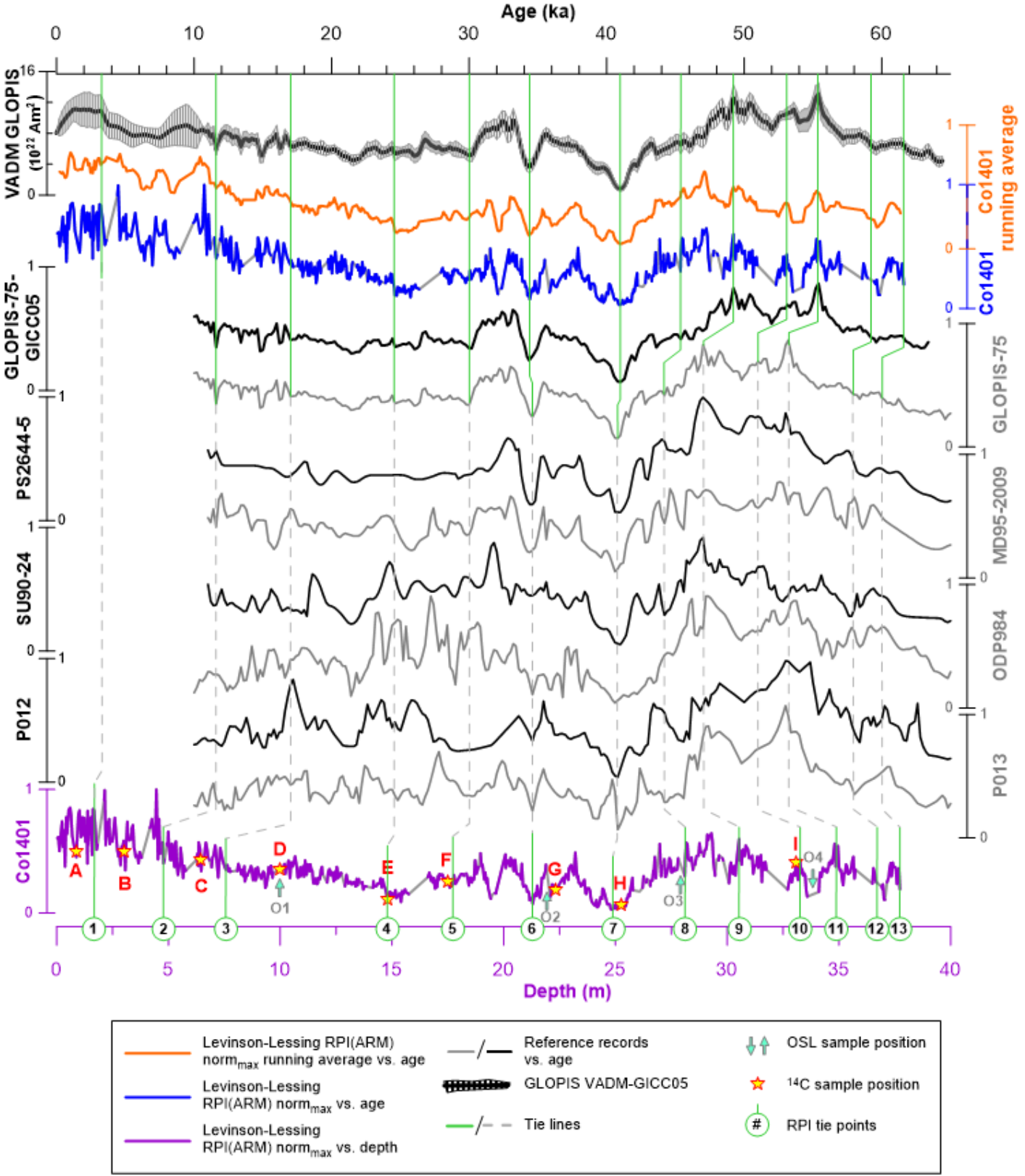

Fig. 5: Tuning of the RPI(ARM) of Co1401 to six northern individual records of GLOPIS-75, and the GLOPIS-75 stack. Names of RPI records are given as axis labels. Please note age divergence between GLOPIS-75 and GLOPIS-75-GICC05. Running average of RPI(ARM) of Co1401 vs. age calculated with window width of 5 is shown for better identification of the general trend. All RPI data sets are normalised to the individual maximum values.

The correlation procedure started with the Laschamp geomagnetic excursion, which is tie point (TP) 7 (Table 3). TP 6 was set to the RPI low of the Mono Lake geomagnetic excursion. In contrast to Co1401 and almost all of the individual sites shown in Figure 5, the RPI record of the GLOPIS-75 stack does not have pronounced drops in RPI between these two geomagnetic excursions. The ${ }^{14} \mathrm{C}$ sample $\mathrm{G}(35.78 \pm 0.59 \mathrm{ka}$ cal. BP $)$ provides an age for the decline in the RPI at lake Levinson-Lessing. The OSL sample $\mathrm{O} 2(32.6 \pm 2.1 \mathrm{ka})$ is slightly younger than expected from the age model but overlaps within its 2 -sigma 
uncertainties (Fig. 3). The position of TP 5 in Co1401 was chosen to represent the RPI minimum before the pronounced RPI increase visible between $~ 30-32 \mathrm{ka}$ in GLOPIS-75 and MD95-2009, and to a lesser extend in P013 and PS2644-5. TP 5 was placed on the RPI low best supported by the ${ }^{14} \mathrm{C}$ sample F (30.26 $\pm 0.77 \mathrm{ka} \mathrm{cal}$. BP). Similarly, but starting from the RPI feature

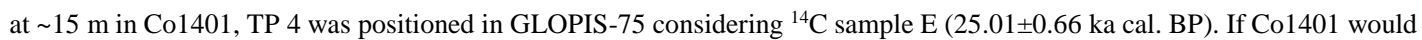
be solely correlated to GLOPIS-75, the minima below $15 \mathrm{mcd}$ in Co1401 would likely be matched to the minima at $\sim 21$ ka in GLOPIS to delineate areas with similar trends (Fig. 5). In such a correlation scheme, TP 4 would be shifted to younger ages. The resulting age model (dashed line in Fig. 6a) would be supported by the age of OSL sample O1 (17.6 $\pm 1.0 \mathrm{ka})$, but at least ${ }^{14} \mathrm{C}$ sample $\mathrm{E}$ and, depending on downward correlation, possibly ${ }^{14} \mathrm{C}$ sample $\mathrm{F}$ would be too old. Therefore, we tentatively follow the correlation scheme that fit to the ages of the ${ }^{14} \mathrm{C}$ samples $\mathrm{E}$ and $\mathrm{F}$, which is still within a 2-sigma error of the age of O1. This decision is supported by the similarity of the RPI of Co1401, MD95-2009 and SU90-24 in the section between TP 4 and TP 5.

The depth interval between TP 3 and TP 4 is the largest between the tie points, because no distinctive correlation features are present in Co1401. The age of ${ }^{14} \mathrm{C}$ sample D $(24.26 \pm 0.37 \mathrm{ka}$ cal. BP) was not considered, because admixture of tiny coal fragments has been detected, which might result in erroneously high ages. The upward increasing trend in RPI visible in Co1401 is also present in GLOPIS-75, PS2644-5, MD95-2009 and SU90-24, albeit in a more attenuated form. TP 3 ties the depth level of Co1401 to the age of GLOPIS-75, at which the amplitude of variations gets larger towards the top. Beside GLOPIS-75, the course of the RPI curve of Co1401 between TP 3 and TP 2 is similar to P012, P013, ODP984, and SU90-24. TP 2 is set to an RPI minimum below the significant increase at $4.8 \mathrm{mcd}$. By this arrangement, the ${ }^{14} \mathrm{C}$ sample $\mathrm{B}(6.09 \pm 0.17 \mathrm{ka}$ cal. BP) is slightly younger than the expected age (Fig. 6a). However, TP 2 and TP 1 are preliminary, as a detailed analysis of the varying magnetic carriers is necessary and will follow in a succedent study. Thus, we do not further discuss TP 2 and TP 1 , nor the deviation from the age of ${ }^{14} \mathrm{C}$ samples B and A (3.35 $\pm 0.10 \mathrm{ka}$ cal. BP) suggested by the age model (Fig. 6a).

Table 3: Tie Points resulting from correlation of RPI(ARM) of core Co1401 with GLOPIS-75-GICC05.

\begin{tabular}{|cccl|}
\hline Short name & Depth (mcd) & Age (ka) & \multicolumn{1}{c|}{ Remark } \\
\hline TP 1 & 1.67 & 3.2 & Preliminary tie point \\
TP 2 & 4.78 & 11.6 & Preliminary tie point \\
TP 3 & 7.57 & 17.0 & \\
TP 4 & 14.79 & 24.6 & Position related to age of ${ }^{14} \mathrm{C}$ sample E \\
TP 5 & 17.73 & 30.0 & Position related to age of ${ }^{14} \mathrm{C}$ sample F \\
TP 6 & 21.30 & 34.4 & Mono Lake Geomagnetic Excursion; \\
& & & Supported by ${ }^{14} \mathrm{C}$ sample G \\
TP 7 & 24.88 & 41.0 & Laschamps Geomagnetic Excursion; \\
& & & Supported by ${ }^{14} \mathrm{C}$ sample $\mathrm{H}$ \\
TP 8 & 28.13 & 45.4 & Supported by OSL sample O3 \\
TP 9 & 30.53 & 49.2 & \\
TP 10 & 33.26 & 53.1 & Position related to age of ${ }^{14} \mathrm{C}$ sample I \\
TP 11 & 34.88 & 55.4 & \\
TP 12 & 36.68 & 59.2 & \\
TP 13 & 37.73 & 61.6 & \\
\hline
\end{tabular}

Due to data gaps obscuring the course of the RPI of Co1401, the correlation with the reference datasets below TP 7 (Laschamps) was difficult. We decided to rely more on the age of ${ }^{14} \mathrm{C}$ sample I $(52.92 \pm 2.06 \mathrm{ka} \mathrm{cal}$. BP) than on the age of OSL sample $\mathrm{O} 4(48.9 \pm 6.4 \mathrm{ka})$ because of the larger error of $\mathrm{O} 4$ and because of the close agreement of ${ }^{14} \mathrm{C}$ samples $\mathrm{G}$ and $\mathrm{H}$ with 
the ages constrained by the geomagnetic excursions. Thus, TP 10 was correlated to an RPI high supported by ${ }^{14} \mathrm{C}$ sample I before TP 8 and TP 9 were placed in the Co1401 to an RPI minimum and maximum, respectively. The resulting age-depth model is supported by the mean value of OSL sample O3 (45.1 $\pm 3.1 \mathrm{ka})$. The course of the RPI of Co1401 between TP 7 and TP 10 is similar to all records shown in Figure 5. TP 11 assigns an age of 55.35 ka to the RPI peak in 34.88 mcd (Table 3). The associated RPI feature is also expressed in PS2644-5 and ODP984 and appears to be slightly shifted to the younger in MD95-2009, P012 and P013 (Fig. 5). This correlation is still within a 2-sigma error of the OSL sample O4. Finally, TP 12 and TP 13 reflect a downcore decrease in RPI as observed in a number of reference records in Figure 5. Although the RPI between TL 11 and TL 13 of Co1401 appears to mimic that of SU90-24 and ODP984, the correlation was complicated due to large data gaps and is thus, associated with a certain degree of uncertainty.

(a)
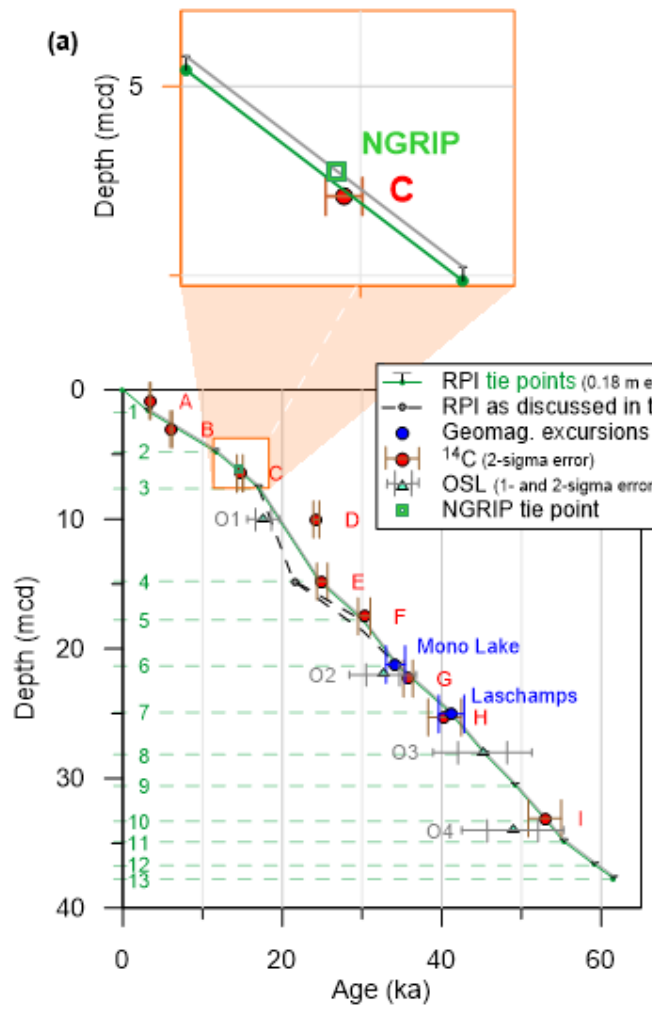

(b)
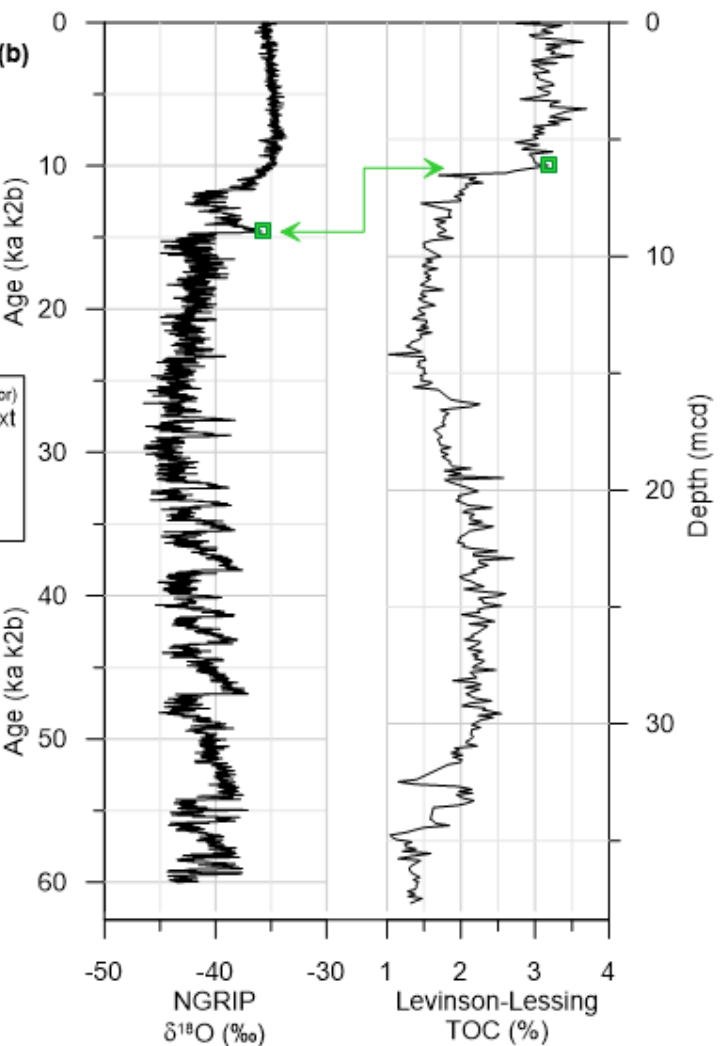

Fig. 6: (a) Age-depth model of the core composite Co1401. Ages of the geomagnetic excursions shown after Laj et al. (2014). The grey line represents the age-depth relationship resulting of a constant lock-in depth of $18 \mathrm{~cm}$. The age of the NGRIP tie point results from the comparison of $\delta^{18} \mathrm{O}$ vs. age and TOC of Co1401 vs. depth (b). Its age is recalculated to BP ages.

The resulting age-depth model of Co1401 gives an age of $\sim 62 \mathrm{ka}$ at $\sim 38$ mcd (Fig. $6 \mathrm{a}$ ). The age-depth model suggests two changes in sedimentation rates. From an average of $62 \mathrm{~cm} \mathrm{ka}^{-1}$ below $14.8 \mathrm{mcd}$, the sedimentation rate increases to $95 \mathrm{~cm}$ ka ${ }^{1}$ above, and becomes reduced again to $45 \mathrm{~cm} \mathrm{ka}^{-1}$ in the uppermost $\sim 7.6$ mcd (17 ka). The latter is similar to the outcome of previous studies on core PG1228 from Lake Levinson-Lessing, which suggested sedimentation rates between 46 and $75 \mathrm{~cm}^{\mathrm{k}}{ }^{-}$

${ }^{1}$ for the Holocene (Hahne and Melles, 1999). For the complete core PG1228, a mean sedimentation rate of $70 \mathrm{~cm}$ ka-1 (Ebel et al., 1999) and a basal age of $\sim 32 \mathrm{ka}$ in $22 \mathrm{~m}$ depth (Andreev et al., 2003) were determined. The somewhat lower average 
value of $62 \mathrm{~cm} \mathrm{ka}^{-1}$ in the sediment $<38.8 \mathrm{ka}$ in Co1401 may be explained by the more distal position of this coring site to the major sediment supply from the Krasnaya River (Lebas et al., 2019). However, it must be noted that the age model of PG1228 (Andreev et al., 2003) is based on uncalibrated ages for both, the dating of the macrofossil remains and humic acids, as well as of the definition of pollen zones and their correlation with the respective zones in other dated records. Thus, direct comparison of the ages from age model of PG1228 with the result of this study is not recommended. However, the offset of the ${ }^{14} \mathrm{C}$ dates by several thousand years compared to the regional pollen chronology described by Andreev et al. (2003) seems to be independent of relative changes in the absolute age scale. A similar age deviation could not be found between the ${ }^{14} \mathrm{C}$ ages and the palaeomagnetically-derived chronology. This is particularly evident from the consistency of the ages of the ${ }^{14} \mathrm{C}$ samples $\mathrm{G}$ and $\mathrm{H}$ in relation to the geomagnetic excursions. Also, the lower sedimentation rates for an unknown duration sometime between about 17-8 ka BP, which is reported by Andreev et al. (2003) for PG1228, seems not to be expressed in Co1401. Instead, a slowdown of the sediment accumulation towards the top is supported by the correlation of the TOC curve with the NGRIP $\delta^{18} \mathrm{O}$ dataset (Svensson et al. 2008, and references therein). Assuming that the TOC signal responds without time delay to the change in global ice volume, an age of $14.6 \mathrm{ka}(\mathrm{k} 2 \mathrm{~b})$ is assigned to 6.12 med (Fig. $6 \mathrm{~b}$ ).

420 This Co1401-TOC to NGRIP suggests a time lag resulting from a lock-in depth of $\sim 18 \mathrm{~cm}$ (magnified section in Fig 6a), though this is only a rough estimation. Uncertainties arise from the correlation schemes of Co1401-TOC to NGRIP and Co1401-RPI to GLOPIS-75, as well as from is the influence of TP 2, which is only preliminary. It is also not known whether this value can be applied to sections at greater depths. Compared to the lock-in depth suggested for the Swedish lakes Kälksjön and Gyltigesjön (cf., section 4.3), the $18 \mathrm{~cm}$ estimated for Co1401 seems to be quite low. The smoothing effect associated with higher lock-in depths would explain the low variability of the RPI of Co1401 compared to the reference records with lower accumulation rates. Thus, we suggest the value of $18 \mathrm{~cm}$ to be a minimum estimation for the lock-in depth at lake LevinsonLessing.

\subsection{Implications for the High Arctic}

During the Holocene, the geomagnetic field in the High Arctic exhibits important differences in its secular variation (PSV) and RPI behaviour compared to midlatitude and Low Arctic records (e.g., St-Onge and Stoner, 2011; Lund et al., 2016). In contrast, hardly any conclusions can be drawn about the behaviour of the EMF in the High Arctic during the Late Pleistocene. The few available records covering this period mainly originate from the central Arctic Ocean and show sedimentation rates of $<8 \mathrm{~cm} \mathrm{ka}^{-1}$. (e.g., Nowaczyk et al., 2003; Polyak et al., 2009). In addition to the resulting low temporal resolution, the interpretation of the palaeomagnetic evidence of these sites was complicated by inconsistencies in PSV and RPI. As explanations for these phenomena, magnetic excursions and diagenetically-induced self-reversals during maghemitization were discussed (e.g., O'Regan et al., 2008; Xuan and Channell, 2010). Just recently, however, the magnetic records of the Arctic Ocean have been shown to be strongly influenced by diagenetic processes that vary in intensity (Wiers et al., 2019; Wiers et al., 2020). This may call into question a number of palaeomagnetic data from marine sites of the Arctic and further thins out the available data. The continuous and high-resolution sediment record of core Co1401 thus, represents an exceptional archive for palaeomagnetic and palaeoenvironmental research. A recent study in the Barents Sea has provides another data set that does not report problems like those in the Arctic Ocean (Caricchi et al., 2019; Caricchi et al., 2020). However, the comparison of the RPI record of Co1401 to the respective sites (GS191-01PC and GS191-02PC) unveil large differences in the amplitude of RPI variations (Fig. 7). The overall significantly lower variability in the Levinson-Lessing Lake record may be due to the differing sedimentary processes. In contrast to the largely uniform lithology, overall constant accumulation and low variability in grain-size spectra of Co1401, marine cores are characterized by high variability with respect to all of these properties. The sedimentation rates of GS191-01PC and GS191-02PC are reported to average $46 \mathrm{~cm} \mathrm{ka}^{-1}$ and $29 \mathrm{~cm} \mathrm{ka}^{-1}$, respectively, but the lithology includes bioturbated mud, massive silt layers, and layers with sometimes massive concentrations 
of pebbles and cobbles (ice rafted debris; Caricchi et al., 2019). Nevertheless, most parts below the Mono Lake geomagnetic excursion in Co1401 (marked in royal blue and black in Fig.7), correlate well with those in GS191-02PC. As in most individual northern Atlantic records (Fig. 5), Barents Sea records indicate a RPI decrease between the Laschamps geomagnetic excursion and a data gap obscuring the Mono Lake excursion. Accordingly, this seems to be a characteristic of the EMF at high northern latitudes, and the feature was averaged out by the global distribution of records combined in GLOPIS-75. Towards younger ages, a correlation of the Barents Sea records and Co1401 is prevented by the uneventful course of the RPI of Co1401. Only the general increasing trend can be recognized to some extent in the parts of the records coloured in purple (Fig. 7). The sections highlighted in light blue of GS191-01PC and GS191-02PC are characterized by strong loss of RPI intensity. This is opposed to the general trend represented by VADM of GLOPIS-GICC05 and could be related to diagenetic overprinting or a change in the composition of the mineral magnetic influx.

Compared to the Barents Sea records, the Baikal Lake stack shows a much lower RPI variability. Despite the differences in the assigned ages of the Baikal Sea stack, clear analogies to Co1401 are recognizable. This is remarkable, since Peck et al. (1996) report average sedimentation rates as low as $13 \mathrm{~cm} \mathrm{ka}^{-1}$. Despite the 4.7 -fold higher average sedimentation rate in Levinson-Lessing Lake, the characteristics of the RPI do not appear to be better defined or more pronounced. This may indicate that smoothing effects are negligible in both records. This observation holds for the comparison with all color-coded sections of the Baikal stack in Figure 7, though to a lesser extend in the part marked in black, in which the accumulation rates of the Baikal stack are particularly low. The overall strong similarities between Co1401, the GLOPIS-GICC05 VADM, and the Baikal stack of low temporal resolution from $50^{\circ}$ latitude suggest that the dipole component of the EMF dominates the secular variation at the Levinson-Lessing site. It remains an open question whether the latitude of Levinson-Lessing Lake of about $74^{\circ} 3^{\prime}$ is not close enough to the magnetic North pole to record significant non-dipolar features expected inside the tangent cylinder. As mentioned earlier, gradual lockin of magnetic minerals over long periods of time would also be a plausible explanation for the low variability of the PSVs. However, considering the determined sedimentation rates, a uniform lock-in depth of $18 \mathrm{~cm}$ and a corresponding lock-in width of the half of the lock-in depth, we gain a smoothing constant <220 years, which would probably not erase all PSV. Further insights into the magnetic field on the tangential cylinder may arise from future studies combining the results of this study with RPI and PSV data from other sites, or from modelling the behaviour of the EMF in the Eurasian Arctic using the data presented. 


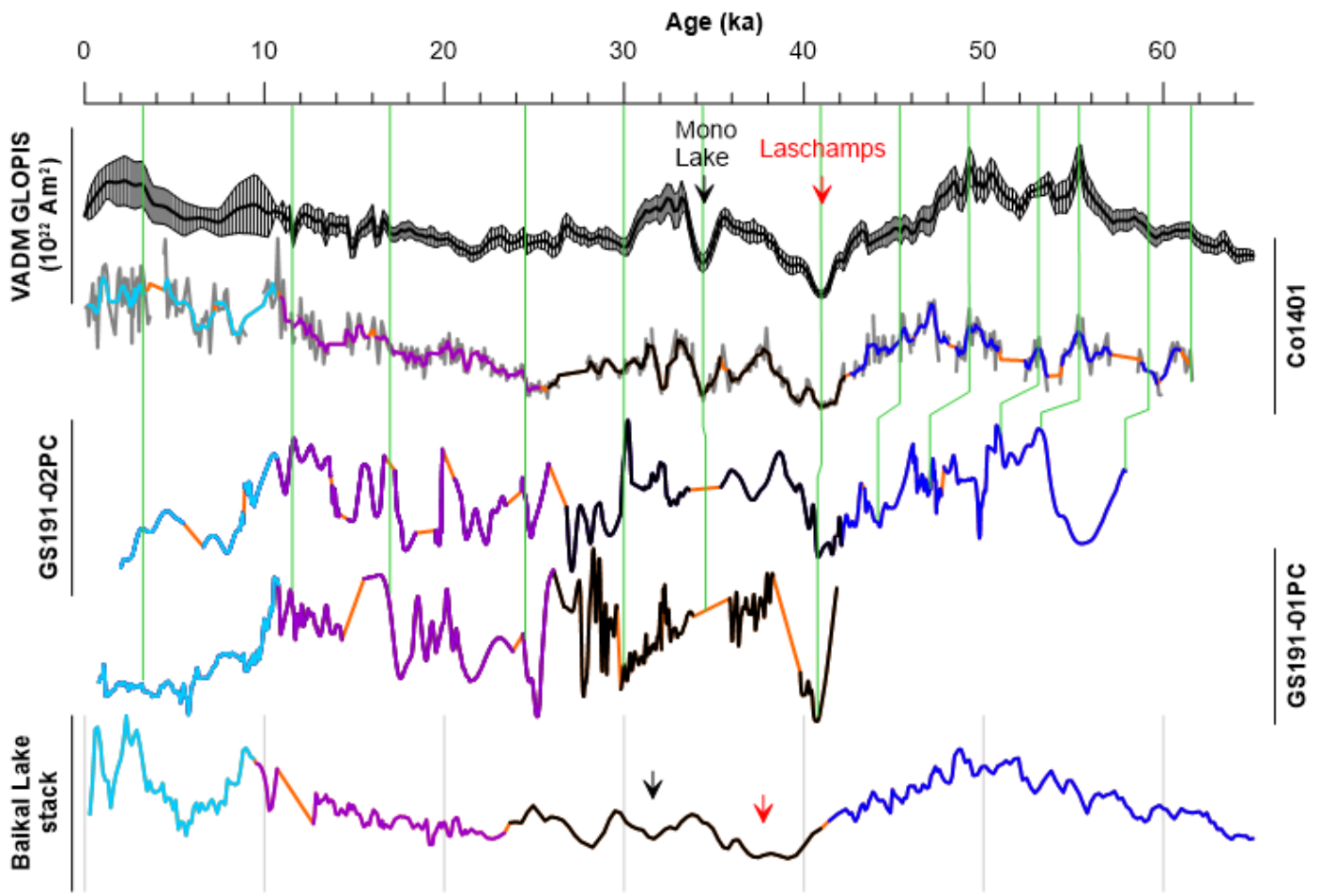

Fig. 7: Comparison of the smoothed RPI of Co1401 (non-smoothed data in grey colours in the background) with RPI records from Lake Baikal (Baikal Lake stack) and the Barents Sea (GS191-01PC and GS191-02PC) and the VADM of GLOPIS-GICC05. For discussion, the RPI records are divided into four parts by colour code (light blue, purple, black, and royal blue). Gaps in the individual records are marked in orange. Please note the different ages assigned to the RPI characteristics of the different datasets, leading to a shift of the patterns against each other (c.f., section 3.3). Tie lines are shown as in Fig. 5. For the Baikal Lake stack, only the main grid lines are provided, as correlation is not readily possible. The locations of geomagnetic excursions are indicated by tie lines and arrows.

\section{Conclusion}

We conducted a high-resolution study of the RPI of composite core Co1401 from lake Levinson-Lessing using ARM, IRM, and $\chi$ as normalizers and obtained consistent results throughout the core. The results for the upper 6.7 mcd indicated a change in magnetic mineralogy including initial greigite formation, and the RPI fluctuations substantially increase in the upper part of the core. The provided correlation of the data $<10 \mathrm{ka}$ is thus, preliminary. Palaeomagnetic events recorded by Co1401 include recordings of the geomagnetic excursions Laschamps and Mono Lake. The age-model for core Co1401 was established by a combined approach using the correlation of the RPI(ARM) to the GLOPIS-75 stack at the GICC05 time scale, AMS ${ }^{14} \mathrm{C}$ and OSL dating. The age-depth model suggests an age of $\sim 62 \mathrm{ka}$ in $\sim 38 \mathrm{mcd}$. Average sedimentation rates shift from $45 \mathrm{~cm} \mathrm{ka}^{-1}$ down to $7.6 \mathrm{mcd}$ (17 ka), via $95 \mathrm{~cm} \mathrm{ka}^{-1}$ between 7.6 and $14.8 \mathrm{mcd}$, to $62 \mathrm{~cm} \mathrm{ka}^{-1}$ below $14.8 \mathrm{mcd}$. The lock-in depth was tentatively set to $18 \mathrm{~cm}$ based on a single tie point obtained from correlation of the downcore changes in TOC with the NGRIP $\delta^{18} \mathrm{O}$ record. This value suggest a smoothing constant of $<220$ years for the complete sedimentation record. Although the course of the characteristic declination is obscured by the lack of overlap of core segments of core Co1401, the PSV data may be used in the future, if data of the general course of the declination from close-by study sites become available. At present, the lacustrine sediment core Co1401 provides the only high-resolution RPI and PSV dataset extending to 62 ka within a radius of more than $1500 \mathrm{~km}$ around lake Levinson Lessing. 


\section{Acknowledgments}

This study was funded by the German Federal Ministry for Education and Research (BMBF) within the scope of the project

PLOT (Paleolimnological Transect, grant nos. 03G0859A and 03F0830A). Datasets for this research are available in Scheidt et al. (2021b). Special thanks are due to Richard Niederreiter, Sverre Aksnes, Andrej Andreev, Anna Cherezova, and Maxim V. Rukhkin for their competent help in collecting core Co1401. We are also very indebted to Carlo Laj and Cathrin Kissel for providing the current GLOPIS-75 data and the data of the individual records.

\section{Data availability statement}

505 Datasets for this research are available in Scheidt et al. (2021).

\section{References}

Alexanderson, H., Backman, J., Cronin, T. M., Funder, S., Ingólfsson, Ó., Jakobsson, M., Landvik, J. Y., Löwemark, L., Mangerud, J., März, C., Möller, P., O'Regan, M., and Spielhagen, R. F.: An Arctic perspective on dating Mid-Late Pleistocene environmental history, Quaternary Science Reviews, 92, 9-31, doi:10.1016/j.quascirev.2013.09.023, 2014.

510 Andreev, A. A., Tarasov, P. E., Siegert, C., Ebel, T., Klimanov, V. A., Melles, M., Bobrov, A. A., Dereviagin, A. Y., Lubinski, D. J., and HUBBERTEN, H. W.: Late Pleistocene and Holocene vegetation and climate on the northern Taymyr Peninsula, Arctic Russia, Boreas, 32, 484-505, doi:10.1111/j.1502-3885.2003.tb01230.x, 2003.

Anisimov, M., and Pospelov, I.: The landscape and geobotanical characteristics of the Levinson-Lessing Lake basin, Byrranga Mountains, central Taimyr, in: Land-Ocean Systems in the Siberian Arctic, Springer, 307-327, 1999.

515 Bolshiyanov, D. Y., and Anisimov, M.: Investigations in the Levinson-Lessing Lake area. Geomorphological studies and landscape mapping. Russian-German cooperation: the expedition Taymyr 1994, Berichte zur Polarforschung, 175, 9-13, 1995.

Buylaert, J. P., Murray, A. S., Gebhardt, A. C., Sohbati, R., Ohlendorf, C., Thiel, C., Wastegård, S., and Zolitschka, B.: Luminescence dating of the PASADO core 5022-1D from Laguna Potrok Aike (Argentina) using IRSL signals from feldspar, Quaternary Science Reviews, 71, 70-80, doi:10.1016/j.quascirev.2013.03.018, 2013.

520 Caricchi, C., Lucchi, R. G., Sagnotti, L., Macrì, P., Di Roberto, A., Del Carlo, P., Husum, K., Laberg, J. S., and Morigi, C.: A HighResolution Geomagnetic Relative Paleointensity Record From the Arctic Ocean Deep-Water Gateway Deposits During the Last 60 kyr, Geochemistry, Geophysics, Geosystems, 20, 2355-2377, doi:10.1029/2018GC007955, 2019.

Caricchi, C., Sagnotti, L., Campuzano, S. A., Lucchi, R. G., Macrì, P., Rebesco, M., and Camerlenghi, A.: A refined age calibrated paleosecular variation and relative paleointensity stack for the NW Barents Sea: Implication for geomagnetic field behavior during the Holocene, Quaternary Science Reviews, 229, doi:10.1016/j.quascirev.2019.106133, 2020.

Chadima, M., and Hrouda, F.: Remasoft 3.0 a user-friendly paleomagnetic data browser and analyzer, Travaux Géophysiques, 27, 20-21, 2006.

Christensen, J. H., Kanikicharla, K. K., Aldrian, E., An, S. I., Cavalcanti, I. F. A., de Castro, M., Dong, W., Goswami, P., Hall, A., and Kanyanga, J. K.: Climate phenomena and their relevance for future regional climate change, in: Climate Change 2013 the Physical Science

530 Basis: Working Group I Contribution to the Fifth Assessment Report of the Intergovernmental Panel on Climate Change, Cambridge University Press, 1217-1308, 2013.

Durcan, J. A., King, G. E., and Duller, G. A.: DRAC: Dose Rate and Age Calculator for trapped charge dating, Quaternary Geochronology, 28, 54-61, 2015.

Ebel, T., Melles, M., and Niessen, F.: Laminated Sediments from Levinson-Lessing Lake, Northern Central Siberia-A 30,000 Year Record

of Environmental History?, in: Land-Ocean Systems in the Siberian Arctic, Springer, Berlin, Heidelberg, 425-435, 1999.

Egli, R., and X. Zhao: Natural remanent magnetization acquisition in bioturbated sediment: General theory and implications for relative paleointensity reconstructions, Geochemistry, Geophysics, Geosystems, 16, 995-1016, 2015. 
Galbraith, R. F., Roberts, R.G., Laslett, G.M., Yoshida, H., and Olley, J.M.: Optical Dating of single and multiple Grains of Quarth from Jinmium Rock Shelter, Northern Australia: Part I, experimental Design and statistical Models, Archaeometry, 41, 339-364, doi:10.1111/j.1475-4754.1999.tb00987.x, 1999.

Geological Map of the Taymyr Peninsula: http://webmapget.vsegei.ru/index.html, access: 01.12.2020, 2014.

Haflidason, H., Zweidorff, J. L., Baumer, M., Gyllencreutz, R., Svendsen, J. I., Gladysh, V., and Logvina, E.: The Lastglacial and Holocene seismostratigraphy and sediment distribution of Lake Bolshoye Shchuchye, Polar Ural Mountains, Arctic Russia, Boreas, 48, 452-469, doi:10.1111/bor.12387, 2019.

545 Hahne, J., and Melles, M.: Climate and Vegetation History of the Taymyr Peninsula since Middle Weichselian Time - Palynological Evidence from Lake Sediments, in: Land-Ocean Systems in the Siberian Arctic: Dynamics and History, edited by: Kassens, H., Bauch, H. A., Dmitrenko, I. A., Eicken, H., Hubberten, H.-W., Melles, M., Thiede, J., and Timokhov, L. A., Springer Berlin Heidelberg, Berlin, Heidelberg, 407-423, 1999.

Jiabo, L., Nowaczyk, N., Frank, U., and Arz, H.: Geomagnetic paleosecular variation record spanning from 40 to 20 ka-implications for the Mono Lake excursion from Black Sea sediments, Earth and Planatary Science Letters, 509, 114-124, 2019.

Kirschvink, J. L.: The least-squares line and plane and the analysis of palaeomagnetic data, Geophysical Journal, Royal Astronomical Society, 62, 699-718, 1980.

Laj, C., Kissel, C., and Beer, J.: High resolution paleointensity stack since 75 kyr (GLOPIS-75) calibrated to absolute values, Geophysical Monograph Series, 255-265, doi:10.1029/145GM19, 2004.

Laj, C., Kissel, C., and Roberts, A. P.: Geomagnetic field behavior during the Iceland Basin and Laschamp geomagnetic excursions: A simple transitional field geometry?, Geochemistry, Geophysics, Geosystems, 7, n/a-n/a, 10.1029/2005GC001122, 2006.

Laj, C., Guillou, H., and Kissel, C.: Dynamics of the earth magnetic field in the 10-75 kyr period comprising the Laschamp and Mono Lake excursions: New results from the French Chaîne des Puys in a global perspective, Earth and Planetary Science Letters, 387, 184-197, doi:10.1016/j.epsl.2013.11.031, 2014.

560 Laj, C., and Kissel, C.: An impending geomagnetic transition? Hints from the past, Frontiers in Earth Science, 3, 10.3389/feart.2015.00061, 2015.

Lang, A., and Zolitschka, B.: Optical dating of annually laminated lake sediments A test case from Holzmaar/Germany, Quaternary Science Reviews, 20, 737-742, doi:10.1016/S0277-3791(00)00067-6, 2001.

Lebas, E., Krastel, S., Wagner, B., Gromig, R., Fedorov, G., Baumer, M., Kostromina, N., and Haflidason, H.: Seismic stratigraphical record 565 of Lake Levinson-Lessing, Taymyr Peninsula: evidence for ice-sheet dynamics and lake-level fluctuations since the Early Weichselian, Boreas, 48, 470-487, doi:10.1111/bor.12381, 2019.

Li, G., Xia, D., Appel, E., Wang, Y., Jia, J., and Yang, X.: A paleomagnetic record in loess-paleosol sequences since late Pleistocene in the arid Central Asia, Earth, Planets and Space, 70, 10.1186/s40623-018-0814-8, 2018.

Lund, S., Keigwin, L., and Darby, D.: Character of Holocene paleomagnetic secular variation in the tangent cylinder: Evidence from the

570 Chukchi Sea, Physics of the Earth and Planetary Interiors, 256, 49-58, doi:10.1016/j.pepi.2016.03.005, 2016.

Lund, S., Benson, L., Negrini, R., Liddicoat, J., and Mensing, S.: A full-vector paleomagnetic secular variation record (PSV) from Pyramid Lake (Nevada) from 47-17 ka: Evidence for the successive Mono Lake and Laschamp Excursions, Earth and Planetary Science Letters, 458, 120-129, 2017.

Martinson, D. G., Pisias, N. G., Hays, J. D., Imbrie, J., Moore, T. C., and Shackleton, N. J.: Age Dating and the Orbital Theory of the Ice Ages: Development of a High-Resolution 0 to 300,000-Year Chronostratigraphy, Quaternary Research, 27, 1-29, doi:10.1016/00335894(87)90046-9, 1987.

Mellström, A., Nilsson, A., Stanton, T., Muscheler, R., Snowball, I., and Suttie, N.: Post-depositional remanent magnetization lock-in depth in precisely dated varved sediments assessed by archaeomagnetic field models, Earth and Planetary Science Letters, 410, 186-196, doi:10.1016/j.eps1.2014.11.016, 2015.

580 Murray, A. S., and Wintle, A. G.: The single aliquot regenerative dose protocol: potential for improvements in reliability, Radiation Measurements, 37, 377-381, doi:10.1016/S1350-4487(03)00053-2, 2003.

Niessen, F., Ebel, T., Kopsch, C., and Fedorov, G. B.: High-Resolution Seismic Stratigraphy of Lake Sediments on the Taymyr Peninsula, Central Siberia, in: Land-Ocean Systems in the Siberian Arctic: Dynamics and History, edited by: Kassens, H., Bauch, H. A., Dmitrenko, I. A., Eicken, H., Hubberten, H.-W., Melles, M., Thiede, J., and Timokhov, L. A., Springer Berlin Heidelberg, Berlin, Heidelberg, 437-456, 1999. 
Nilsson, A., Suttie, N., and Hill, M. J.: Short-Term Magnetic Field Variations From the Post-depositional Remanence of Lake Sediments, Frontiers in Earth Science, 6, doi:10.3389/feart.2018.00039, 2018.

Nowaczyk, N. R., and Knies, J.: Magnetostratigraphic results from the eastern Arctic Ocean: AMS <sup $>14</$ sup $>\mathrm{C}$ ages and relative palaeointensity data of the Mono Lake and Laschamp geomagnetic reversal excursions, Geophysical Journal International, 140, 185-197, 2000 .

Nowaczyk, N. R., Antonow, M., Knies, J., and Spielhagen, R. F.: Further rock magnetic and chronostratigraphic results on reversal excursions during the last $50 \mathrm{ka}$ as derived from northern high latitudes and discrepancies in precise AMS <sup $>14</$ sup $>\mathrm{C}$ dating, Geophysical Journal International, 155, 1065-1080, 2003.

O'Regan, M., King, J., Backman, J., Jakobsson, M., Pälike, H., Moran, K., Heil, C., Sakamoto, T., Cronin, T. M., and Jordan, R. W.: 595 Constraints on the Pleistocene chronology of sediments from the Lomonosov Ridge, Paleoceanography, 23, doi:10.1029/2007PA001551, 2008.

Panovska, S., Constable, C. G., and Korte, M.: Extending Global Continuous Geomagnetic Field Reconstructions on Timescales Beyond Human Civilization, Geochemistry, Geophysics, Geosystems, 19, 4757-4772, doi:10.1029/2018GC007966, 2018.

Pavón-Carrasco, F. J., Osete, M. L., Torta, J. M., and De Santis, A.: A geomagnetic field model for the Holocene based on archaeomagnetic and lava flow data, Earth and Planetary Science Letters, 388, 98-109, doi:10.1016/j.epsl.2013.11.046, 2014.

Peck, J. A., King, J. W., Colman, S. M., and Kravchinsky, V. A.: An 84-kyr paleomagnetic record from the sediments of Lake Baikal, Siberia, Journal of Geophysical Research: Solid Earth, 101, 11365-11385, doi:10.1029/96JB00328, 1996.

Polyak, L., Bischof, J., Ortiz, J. D., Darby, D. A., Channell, J. E., Xuan, C., Kaufman, D. S., Løvlie, R., Schneider, D. A., and Eberl, D. D.: Late Quaternary stratigraphy and sedimentation patterns in the western Arctic Ocean, Global and Planetary Change, 68, 5-17, doi:10.1016/j.gloplacha.2009.03.014, 2009.

Porter, Claire; Morin, Paul; Howat, Ian; Noh, Myoung-Jon; Bates, Brian; Peterman, Kenneth; Keesey, Scott; Schlenk, Matthew; Gardiner, Judith; Tomko, Karen; Willis, Michael; Kelleher, Cole; Cloutier, Michael; Husby, Eric; Foga, Steven; Nakamura, Hitomi; Platson, Melisa; Wethington, Michael, Jr.; Williamson, Cathleen; Bauer, Gregory; Enos, Jeremy; Arnold, Galen; Kramer, William; Becker, Peter; Doshi, Abhijit; D'Souza, Cristelle; Cummens, Pat; Laurier, Fabien; Bojesen, Mikkel, 2018, "ArcticDEM", doi:10.7910/DVN/OHHUKH, Harvard

Reimer, P. J., Austin, W. E. N., Bard, E., Bayliss, A., Blackwell, P. G., Bronk Ramsey, C., Butzin, M., Cheng, H., Edwards, R. L., Friedrich, M., Grootes, P. M., Guilderson, T. P., Hajdas, I., Heaton, T. J., Hogg, A. G., Hughen, K. A., Kromer, B., Manning, S. W., Muscheler, R., Palmer, J. G., Pearson, C., van der Plicht, J., Reimer, R. W., Richards, D. A., Scott, E. M., Southon, J. R., Turney, C. S. M., Wacker, L., Adolphi, F., Büntgen, U., Capano, M., Fahrni, S. M., Fogtmann-Schulz, A., Friedrich, R., Köhler, P., Kudsk, S., Miyake, F., Olsen, J., 615 Reinig, F., Sakamoto, M., Sookdeo, A., and Talamo, S.: The IntCal20 Northern Hemisphere Radiocarbon Age Calibration Curve (0-55 CAL kBP), Radiocarbon, 1-33, https://doi:10.1017/RDC.2020.41, 2020.

Roberts, A. P., Tauxe, L., and Heslop, D.: Magnetic paleointensity stratigraphy and high-resolution Quaternary geochronology: successes and future challenges, Quaternary Science Reviews, 61, 1-16, 2013.

Scheidt, S., Hambach, U., and Rolf, C.: A consistent magnetic polarity stratigraphy of late Neogene to Quaternary fluvial sediments from the Heidelberg Basin (Germany): A new time frame for the Plio-Pleistocene palaeoclimatic evolution of the Rhine Basin, Global and Planetary Change, 127, 103-116, https://doi.org/10.1016/j.gloplacha.2015.01.004, 2015.

Scheidt, S., Egli, R., Lenz, M., Rolf, C., Fabian, K., and Melles, M.: Mineral Magnetic Characterization of high-latitude Sediments from Lake Levinson-Lessing, Siberia, Geophysical Research Letters, 48, e2021GL093026, https://doi.org/10.1029/2021GL093026, 2021 a.

Scheidt, S., Egli, R., Rolf, C., and M. Melles, Magnetic characterization and paleomagnetic analyses of lacustrine sediments from Levinson-

Lessing Lake, Siberia, fighshare. doi:10.6084/m9.figshare.c.5369129.v1, 2021b.

Siegert, C., and Bolshiyanov, D.: Russian-German cooperation: the expedition TAYMYR 1994, Berichte zur Polarforschung (Reports on Polar Research), 175, 1995.

Simon, Q., Thouveny, N., Bourlès, D. L., Valet, J.-P., and Bassinot, F.: Cosmogenic 10Be production records reveal dynamics of geomagnetic dipole moment (GDM) over the Laschamp excursion (20-60 ka), Earth and Planetary Science Letters, 550, 116547, 
St-Onge, G., and Stoner, J.: Paleomagnetism Near the North Magnetic Pole: A Unique Vantage Point for Understanding the Dynamics of the Geomagnetic Field and Its Secular Variations, Oceanography, 24, 42-50, doi:10.5670/oceanog.2011.53, 2011.

Stoner, J. S., and St-Onge, G.: Chapter Three Magnetic Stratigraphy in Paleoceanography: Reversals, Excursions, Paleointensity, and Secular Variation, in: Proxies in Late Cenozoic Paleoceanography, Developments in Marine Geology, 99-138, 2007.

Svensson, A., Andersen, K. K., Bigler, M., Clausen, H. B., Dahl-Jensen, D., Davies, S. M., Johnsen, S. J., Muscheler, R., Parrenin, F., Rasmussen, S. O., Röthlisberger, R., Seierstad, I., Steffensen, J. P., and Vinther, B. M.: A 60000 year Greenland stratigraphic ice core chronology, Climate of the Past, 4, 47-57, doi:10.5194/cp-4-47-2008, 2008.

Rethemeyer, J., Gierga, M., Heinze, S., Stolz, A., Wotte, A., Wischhöfer, P., Berg, S., Melchert, J. O., and Dewald, A.: Current Sample Preparation and Analytical Capabilities of the Radiocarbon Laboratory at CologneAMS, Radiocarbon, 61, 1449-1460, 10.1017/RDC.2019.16, 2019.

Tauxe, L.: Sedimentary records of relative paleointensity of the geomagnetic field: theory and practice, Reviews of geophysics, 31, 319-354, doi:10.1029/93RG01771, 1993.

Tauxe, L., Pick, T., and Kok, Y. S.: Relative paleointensity in sediments: A Pseudo-Thellier Approach, Geophysical Research Letters, 22, 2885-2888, doi:10.1029/95GL03166, 1995.

Tauxe, L., Steindorf, J. L., and Harris, A.: Depositional remanent magnetization: Toward an improved theoretical and experimental foundation, Earth and Planetary Science Letters, 244, 515-529, doi:10.1016/j.epsl.2006.02.003, 2006.

650 Torsvik, T. H., and Andersen, T. B.: The Taimyr fold belt, Arctic Siberia: timing of prefold remagnetisation and regional tectonics, Tectonophysics, 352, 335-348, doi:10.1016/S0040-1951(02)00274-3, 2002.

Valet, J.-P., Tanty, C., and Carlut, J.: Detrital magnetization of laboratory-redeposited sediments, Geophysical Journal International, 210, 34-41, 10.1093/gii/ggx139, 2017.

van der Bilt, W. G. M., Bakke, J., Vasskog, K., D'Andrea, W. J., Bradley, R. S., and Ólafsdóttir, S.: Reconstruction of glacier variability from lake sediments reveals dynamic Holocene climate in Svalbard, Quaternary Science Reviews, 126, 201-218, doi:10.1016/j.quascirev.2015.09.003, 2015.

Vereș, D. S..: A comparative study between loss on ignition and total carbon analysis on mineralogenic sediments, Studia UBB Geologia, 47, 171-182, http://dx.doi.org/10.5038/1937-8602.47.1.13 2002.

Walderhaug, H. J., Eide, E. A., Scott, R. A., Inger, S., and Golionko, E. G.: Palaeomagnetism and 40Ar/39Ar geochronology from the South

660 Taimyr igneous complex, Arctic Russia: a Middle-Late Triassic magmatic pulse after Siberian flood-basalt volcanism, Geophysical Journal International, 163, 501-517, doi:10.1111/j.1365-246X.2005.02741.x, 2005.

Wessel, P., Luis, J. F., Uieda, L., Scharroo, R., Wobbe, F., Smith, W. H. F., and Tian, D.: The Generic Mapping Tools Version 6, Geochemistry, Geophysics, Geosystems, 20, 5556-5564, doi:10.1029/2019GC008515, 2019.

Wiers, S., Snowball, I., O'Regan, M., and Almqvist, B.: Late Pleistocene Chronology of Sediments From the Yermak Plateau and Uncertainty 665 in Dating Based on Geomagnetic Excursions, Geochemistry, Geophysics, Geosystems, 20, 3289-3310, doi:10.1029/2018GC007920, 2019. Wiers, S., Snowball, I., O'Regan, M., Pearce, C., and Almqvist, B.: The Arctic Ocean Manganese Cycle, an Overlooked Mechanism in the Anomalous Palaeomagnetic Sedimentary Record, Frontiers in Earth Science, 8, doi:10.3389/feart.2020.00075, 2020.

Xuan, C., and Channell, J. E. T.: Origin of apparent magnetic excursions in deep-sea sediments from Mendeleev-Alpha Ridge, Arctic Ocean, Geochemistry, Geophysics, Geosystems, 11, doi:10.1029/2009GC002879, 2010.

670 Zander, A., and Hilgers, A.: Potential and limits of OSL, TT-OSL, IRSL and pIRIR\&lt;sub\&gt;290\&lt;/sub\&gt; dating methods applied on a Middle Pleistocene sediment record of Lake El'gygytgyn, Russia, Climate of the Past, 9, 719-733, 10.5194/cp-9-719-2013, 2013. 